Certification of the Relative Molecular Mass and the Intrinsic Viscosity of SRM 2886, a Polyethylene of Narrow Molecular Mass Distribution

\section{M. Guttman \\ J. R. Maurey \\ W. R. Blair}

U. S. DEPARTMENT OF COMMERCE Technology Administration Polymers Division

National Institute of Standards

and Technology

Gaithersburg, MD 20899

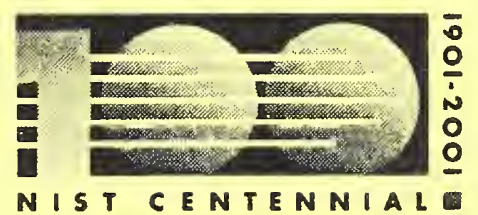

NIST CENTENNIAL
$Q C$

100

.456

1.0.6487

2000

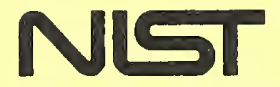

National Institufe of Standards and Technology

Technology Administration

U.S. Department of Commerce

C. 2 



\section{Certification of the Relative Molecular Mass and the Intrinsic Viscosity of SRM 2886, a Polyethylene of Narrow Molecular Mass Distribution}

\section{M. Guttman \\ J. R. Maurey W. R. Blair}

U. S. DEPARTMENT OF COMMERCE Technology Administration Polymers Division National Institute of Standards and Technology

Gaithersburg, MD 20899

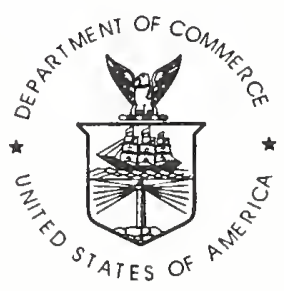

U.S. DEPARTMENT OF COMMERCE William M. Daley, Secretary

TECHNOLOGY ADMINISTRATION

Dr. Cheryl L. Shavers, Under Secretary of Commerce for Technology

NATIONAL INSTITUTE OF STANDARDS

AND TECHNOLOGY

Raymond G. Kammer, Director 



\title{
Certification of the Relative Molecular Mass and the Intrinsic Viscosity of SRM 2886, a Polyethylene of Narrow Molecular Mass Distribution
}

\author{
C. M. Guttman, J. R. Maurey, and W.R. Blair \\ Polymers Division \\ NIST \\ Gaithersburg, MD 20899
}

file: SRM28863_final.doc

Certain commercial materials and equipment are identified in this paper in order to specify adequately the experimental procedure. In no case does such identification imply recommendation or endorsement by the National Institute of Standards and Technology, nor does it imply necessarily the best available for the purpose.

According to ISO 31-8, the term "Molecular Weight" has been replaced by Relative Molecular Mass, symbol $M_{\mathrm{r}}$. Thus, if this nomenclature and notation were followed in this publication, one should write $M_{r, w}$ instead of the historically conventional $\mathrm{M}_{\mathrm{w}}$ for the weight average molecular weight with similar changes for $M_{n}, M_{z}$, and $M_{v} . M_{w}$ would be called the "Mass Average Relative Molecular Mass." The conventional notation, rather than the ISO notation, has been used in this publication.

Final report prepared for the sponsors, the NIST Standard Reference Materials Program (SRMP). 


\begin{abstract}
The certification of a polyethylene standard reference material, SRM 2886, is described. The $\mathrm{M}_{\mathrm{w}}$ of SRM 2886 by light scattering was determined to be $87.0 \times 10^{+3} \mathrm{~g} / \mathrm{mol}$ with a sample standard deviation of $2.2 \times 10^{+3} \mathrm{~g} / \mathrm{mol}$. A combined expanded uncertainty for this light scattering $M_{w}$ determination, including systematic and random uncertainties, was estimated to be $6.0 \times 10^{+3}$ $\mathrm{g} / \mathrm{mol}$. The intrinsic viscosity of SRM 2886, by solution viscosity, in 1,2,4-trichlorobenzene was determined to be $157.8 \mathrm{~mL} / \mathrm{g}$ with a sample standard deviation of $1.8 \mathrm{~mL} / \mathrm{g}$. A combined expanded uncertainty for this intrinsic viscosity determination was 2.1 $\mathrm{mL} / \mathrm{g}$. The bottle-to-bottle variation of the SRM was checked by size exclusion chromatography (SEC) and found to be negligible.
\end{abstract}




\subsection{Introduction}

This report describes the certification of the $\mathrm{M}_{w}$ by light scattering and intrinsic viscosity (often called the limiting viscosity number [1]) in 1,2,4-trichlorobenzene (TCB) at $130^{\circ} \mathrm{C}$ of a linear polyethylene, SRM 2886. The material was obtained from fractionating SRM 1475, as described previously [2]. In the early 1970 's, some of this fractionated material was used in the preparation of SRM 1482, SRM 1483, and SRM 1484. Other fractions from the separation had been stored in the Polymers Division in the intervening years. From this material three new narrow mass fraction SRMs are being certified. This reports describes the cleanup, the $\mathrm{M}_{\mathrm{w}}$ by light scattering and the intrinsic viscosity measurements on one of these fractions, a moderate molecular mass

polyethylene. Bottle-to-bottle homogeneity on the final packaged material was determined by size exclusion chromatography (SEC).

\subsection{Preparation, Bottling, and Handling of SRM 2886}

\subsection{Preparation of the SRM}

The $\mathrm{M}_{\mathrm{w}}$ standard, SRM 2886, is a fraction of SRM 1475. The fractionation was described in reference [2]. Fractions of SRM 1475 that had nearly the same SEC trace were combined to obtain enough material for the SRM 2886. The fractions contained both fine powders and larger aggregates and some dirt particles were evident, as well as a slight yellowing. It was evident that these fractions needed to be cleaned by recrystallization from solution prior to certification. This process is described in section 2.1.1.

Subsequent to recrystallization from solution as fine powders the material was sieved together through a sieve with $1.65 \mathrm{~mm}$ openings (C E Tyler, Mentor Ohio, 10 meshes to the inch) and then well mixed dry in a stainless steel tray $30 \mathrm{~cm}$ x $50 \mathrm{~cm}$. SEC was performed on samples taken from different positions in this tray to confirm the adequacy of mixing. The contents of the tray were sent to NIST Standard Reference Materials Program (SRMP) for bottling.

\subsubsection{Recrystallization from Solution}

Details of the recrystallization procedure and apparatus are given in Appendix I. As the SRM 2886 material was the first of the three new SRMs to be purified by recrystallization, the procedure used departs in many respects from the general recrystallization procedure described in Appendix I. The general recrystallization procedure evolved with improvements designed after experience with the recrystallization of the moderate molecular mass polyethylene fraction.

SEC testing on the material before the recrystallization from solution indicated that the starting material of SRM 2886 had a unimodal mass distribution. The $314 \mathrm{~g}$ starting material was divided into two parts and recrystallized in separate batches. Each part was dissolved in $13 \mathrm{~L}$ of 1,2,4trichlorobenzene (TCB) to form a solution of about $10 \mathrm{~g} / \mathrm{L}$ at $130{ }^{\circ} \mathrm{C}$. The polymer was dissolved 
in the TCB at $135^{\circ} \mathrm{C}$ to $140{ }^{\circ} \mathrm{C}$. The solution was then cooled rapidly to $110^{\circ} \mathrm{C}$ and subsequently allowed to cool slowly overnight to form the crystal product.

The stirring was discontinued to allow the PE crystals to float to the top of the TCB phase. After the PE crystals had floated to the top of the TCB phase, a large sample of the TCB subnatant was rapidly discharged through the drain valve located at the bottom of the recrystallization flask in order to remove any high-density insoluble debris, which had settled to the bottom. The remainder of the TCB subnatant was allowed to drain slowly, and directly (without filtration) into a receiving bottle, until the supernatant PE slurry entered the top of the drain valve.

The PE supernatant was drained into a filter cup. Since SEC tests had indicated that the starting material was unimodal in mass distribution, fractional crystallization was unnecessary, and the filtration was conducted at ambient temperature.

The residual polymer was recovered from the inside surfaces of the recrystallization flask by refluxing xylene in the flask and draining the hot xylene washes into a beaker. After the hot xylene washes had cooled to ambient temperature, the recrystallized PE was recovered in the filter cup. The recrystallized PE recovered from the hot xylene washes was processed separately from the material that had not been redissolved in hot xylene.

The crystallized PE recovered in the filter cup was extracted three times in petroleum ether only. The PE was transferred to crystallizing dishes, without the bulk form being subjected to fine division, in preparation for removal of residual solvent and petroleum ether in a vacuum oven.

The crystallizing dishes were placed in a vacuum oven held at $50{ }^{\circ} \mathrm{C}$ to $60{ }^{\circ} \mathrm{C}$. A vacuum was applied to the samples through a liquid nitrogen cold trap using the house utility vacuum system (approx.0.7 kPa). The initial result of such heating under vacuum was condensation of TCB vapors inside the oven and an excessive recovery of TCB in the cold trap. After the vacuum heating could be conducted without such excessive condensation of vapors, a greater vacuum was applied by a laboratory vacuum pump until negligible condensate was collected in the cold trap. The purified PE, much of it in the form of large lumps, was finely divided inside a beaker by forceful manipulation with a stainless steel spatula. The finely divided PE was transferred to preweighed ointment jars. The jars of finely divided PE were placed in the vacuum oven, and vacuum heating was resumed. The vacuum heating was continued until constant mass of the jars indicated that the residual solvent had probably been removed quantitatively. The experience gained in removing residual TCB from a PE crystal preparation, which had been extracted only in petroleum ether, engendered in part the subsequent general practice of additional extraction in warm xylene before extraction in petroleum ether. The tough resistance of the dried PE lumps to being finely divided also engendered the subsequent general practice of dividing the polymer into fine particles immediately following its final extraction in petroleum ether.

As a final check for solvent entrapment in the polymer, about $0.6 \mathrm{~g}$ of the polymer was weighed and then was placed in a vacuum over at $50{ }^{\circ} \mathrm{C}$ for $45 \mathrm{~h}$. The sample was reweighed. No mass loss was observed. 


\subsection{Packaging and Sampling of SRM 2886}

Of the approximately $300 \mathrm{~g}$ of purified material approximately $220 \mathrm{~g}$ was packaged in about 700 vials containing about $0.3 \mathrm{~g}$ each. In the following report, the containers holding SRM 2886 will be referred to as vials. The remaining polymer was divided into two lots, designated as division 1 supply and division 2 supply. These large lot samples were used to supply some of the material used in the light scattering and intrinsic viscosity measurements. Prior to the use of material from these division supply bottles, however, we ascertained that these samples were identical to the material in the vials. (See Section 2.3).

The entire set of SRM 2886 vials was divided into 23 subsets of 30 or 31 vials. One vial was randomly selected from each subset of SRM 2886 for homogeneity testing. The first and last bottled vials were also taken. These vials and the two division supply lots were used in the SEC homogeneity testing described below. All these materials were used in the light scattering determinations and intrinsic viscosity determinations described in later sections.

\subsection{Homogeneity Testing}

Homogeneity testing was accomplished using SEC. In this study, a Waters 150-C ALC/GPC Liquid Chromatograph (Waters Corp., Milford, MA) with a differential refractive index (DRI) detector and three Waters styragel columns, HT-6, HT-4, and HT-3, were used. The chromatograms were taken at $0.8 \mathrm{~mL} / \mathrm{min}$ solvent flow rate. The injector and column compartments of the Waters $150-\mathrm{C} \mathrm{ALC/GPC}$ were controlled at $130^{\circ} \mathrm{C}$ for all measurements. The solvent, 1,2,4-trichlorobenzene (TCB), was obtained from Aldrich Chemical (1,2,4trichlorobenzene, 99+\%, spectrophotometric grade, Aldrich Chemical, Milwaukee, WI) and used as received. Santonox (5-tert-Butyl-4-hydroxy-2-methylphenyl sulfide), also obtained from Aldrich Chemical, was added to the solvent at about $0.1 \mathrm{~g} / \mathrm{L}$ as an antioxidant.

Vials of SRM 2886 were obtained from SRMP as described above. The polymer in the two division supply lots was also included in this test. A mass of $1.9 \mathrm{mg}$ to $2.9 \mathrm{mg}$ of the polyethylene was weighed into the canister of the Waters auto filtration assembly along with $4 \mathrm{~mL}$ of solvent yielding a concentration of approximately $0.6 \mathrm{~g} / \mathrm{L}$. Hexadecane, at $0.03 \mathrm{~mL} / \mathrm{L}$, was added to the solutions of polymer and solvent as a marker to indicate the reproducibility of the solvent volume delivered by the SEC pump for all measurements. Each filtering assembly was heated to $150{ }^{\circ} \mathrm{C}$ in an oven for about $1.5 \mathrm{~h}$ and the solution was shaken at frequent intervals to aid the dissolution. The filter assemblies were placed in the Waters 150-C ALC/GPC injection compartment held at $130{ }^{\circ} \mathrm{C}$ for automatic filtering and injection. Chromatograms were then run with these solutions.

Solutions were prepared from each vial of SRM 2886 sample population and from each of the division supply lots. Two solutions were prepared from each vial selected from those received 
from SRMP and four solutions were prepared from each division bottle. For SRM 2886, this resulted in 58 solutions to be tested. The order used to run the solutions was randomized following the method described in section 1-4 of the handbook by Natrella [3]. Two injections were made from each solution. Because of occasional instrument malfunctions a few solutions had to be run twice. All chromatographic data were obtained during an eight-day period, with 8 solutions measured per day.

After baseline subtraction, the SEC chromatograms were normalized to unit peak height and compared initially by overlaying to determine if there were visible differences outside the noise. The chromatograms from different solutions all superimposed on each other. This preliminary comparison showed that polymer samples taken from all the vials produced identical chromatograms. Further statistical analysis of the chromatograms is discussed in Section 2.3.1.

\subsubsection{Statistical Method to Compare Chromatograms}

\subsubsection{Match Factor}

In previous SEC studies on SRM homogeneity, the match factor was used to compare one chromatogram to all others [4]. The match factor is a correlation coefficient between one chromatogram and another. The match factor is defined by Huber [5] as

$$
\text { Match Factor }=10^{3}\left\{3 x^{*} y-\left(3 x^{*} 3 y\right) / p\right\}^{2} /\left[\left\{3 x^{2}-3 x * 3 x / p\right\}\left\{3 y^{2}-3 y * 3 y / p\right\}\right]
$$

The values $\mathrm{x}$ and $\mathrm{y}$ are the measured signal in the first and second chromatograms, respectively, at the same time in the chromatograms; $p$ is the number of data points. The sums are taken over all data points.

At the extremes, a match factor of zero indicates no match and 1000 indicates identical chromatograms. Generally, values above 990 indicate that the chromatograms are similar. Values between 900 and 990 indicate there is some similarity, but the result should be interpreted with care. All values below 900 are thought to mean that the chromatograms are different $[5,6]$. The method we describe here has been used previously [7].

We obtained the match factor of the entire set of chromatograms, which include two injections for each solution prepared, against the average chromatogram. In the following discussions, we will compare chromatograms against the average chromatogram. As we will see, there is a clustering of the match factor of chromatograms run during the first day that differs from those of later days. Otherwise, all chromatograms are similar, according to the definitions given above.

An ANOVA study, using OMNITAB [8], was made on the match factors obtained from the chromatograms. It indicated that the match factors for the chromatograms from the same vial 
were no different than those from different vials on a level of significance with $\alpha=0.05$ [9]. Moreover, the match factors of chromatograms from the two division supply lots and the vials were indistinguishable using the same significance level with $\alpha=0.05$. The samples were run in groups of 6 to 8 on different days. Using the match factor, we found that chromatograms recorded on the first day were slightly different from subsequent chromatograms on a level of significance with $\alpha=0.05$.

As described above, hexadecane was added to the solutions of polymer and solvent as a marker to indicate the reproducibility of the solvent volume delivered by the SEC pump for all the chromatographic measurements. These hexadecane peaks were widely separated from the peaks for the polyethylene. However, interference peaks at later times resulted in distortions appearing in the baseline associated with the hexadecane peak. This baseline distortion caused some difficulty in the match factor analysis at higher elution volumes. However, a plot of match factors versus chromatograph number over the range of the hexadecane peak showed the same effect as seen in the match factors for the SRM 2886 chromatograms; that is, the chromatograms from the first day showed match factors somewhat lower than those from later days. Thus, we conclude that instrumental factors affected the first day chromatograms. This reinforces our view that there is no discernible difference among any of the vials or the two division supply lots. From the above analysis and the analysis on the match factor discussed earlier, we see more variability in the hexadecane chromatograms than we see in the chromatograms from the polyethylene solutions. From this we conclude that there is no statistically significant difference between the contents of vials sampled from the SRMP supply of SRM 2886 and no difference between the SRMP supply and the two division supply lots.

\subsection{Estimation of Polydispersity Index of SRM 2886}

SEC measurements described in the Section 2.3 were used to estimate the polydispersity index (PD). We used the same columns and solvents as described in Section 2. The instrument for this work was a Waters Alliance GPCV 2000. Columns were calibrated with SRM 1482, SRM 1483 , SRM 1484, SRM 1475, SRM 2885, SRM 2886, and SRM 2887. From the SEC curves for SRM 2886 we estimated the $\mathrm{PD}\left(\mathrm{PD}=\mathrm{M}_{\mathrm{w}} / \mathrm{M}_{\mathrm{n}}\right)$ to be 1.21. No effects of column broadening were taken into account in this calculation, so we expect the value of 1.21 to be an overestimate of the PD.

In a separate calculation, we tried to take the column broadening into account using the Waters Corporation Millennium Software. Using their Axial Dispersion Calculation with peak compression, we found a PD of 1.12.

\subsection{Intrinsic Viscosity of SRM 2886}




\subsection{Measurement of the Intrinsic Viscosity}

Viscosity measurements were made with a Schott-Gerate Ubbelohde micro-viscometer (SchottGerate GMBH, Hofheim, Germany) with a Schott-Gerate constant temperature bath held at $130^{\circ} \mathrm{C}$. Flow times were measured by the Schott-Gerate AVS 400. The solvent, 1,2,4trichlorobenzene (TCB), was obtained from Aldrich Chemical (1,2,4-trichlorobenzene, 99+\%, spectrophotometric grade, Aldrich Chemical, Milwaukee, WI) and used as received. Butylated hydroxytolulene (2,6-Di-tert-butyl-4-methylphenol), also obtained from Aldrich Chemical, was added to the solvent at about $0.7 \mathrm{~g} / \mathrm{L}$ as an antioxidant.

Solution concentrations ranging from $0.2 \mathrm{~g} / \mathrm{L}$ to $2 \mathrm{~g} / \mathrm{L}$ were prepared from independent weighing of polymer and solvent, rather than employing successive dilution techniques. Concentrations were calculated from densities and partial specific volumes determined earlier in this laboratory [10].

The polymer was dissolved by heating the mixture to $135^{\circ} \mathrm{C}$ to $140^{\circ} \mathrm{C}$ in a hot air oven with occasional stirring. Solutions were then transferred to a viscometer by filtering the solution though a syringe and syringe filter heated in the same oven. The syringe filter assembly used was a Swinny Stainless $25 \mathrm{~mm}$ (Millipore Corp., Bedford, MA), while the filter membrane was a PallGelman Sciences ZEFLOUR all Teflon $0.5 \mu \mathrm{m}$ pore size $25 \mathrm{~mm}$ diameter membrane (Pall Corp., Port Washington, NY).

For each polymer concentration, flow times were measured for both solvent and solutions. The AVS 400 is designed to perform a number of preconditioning runs to insure that the solution or solvent comes to temperature equilibrium before the actual measurements were made and recorded. The operation of the AVS 400 took about $2 \mathrm{~min}$ to $2.5 \mathrm{~min}$ for each of the five preconditioning runs. Five flow times were measured on each aliquot of the solvent or the solution. Flow times measured in this viscometer ranged from $40 \mathrm{~s}$ to $60 \mathrm{~s}$.

At the beginning of an overall measurement on a solution, the viscometer was flushed with at least three solvent aliquots. Then, at least two aliquots of solvent were introduced for flow time measurements. Three aliquots of solution were used to flush the viscometer. Three aliquots of solution were then measured. Three aliquots of solvent were used to flush the viscometer. Finally, flow time measurements were made on three aliquots of solvent.

\subsection{Results of Solution Viscosity}

The solution viscosity, $\eta(\mathrm{c})$, may be expanded as a power series in solution concentration, $\mathrm{c},[11]$

$$
\eta(c)=\eta(0)\left(1+a_{1} c+a_{2} c^{2}+\ldots\right)
$$

where $\eta(0)$ is the solvent viscosity.

The relative viscosity is defined as 


$$
(\eta(c)-\eta(0)) /(\eta(0) c)=a_{1}+a_{2} c
$$

The intrinsic viscosity, $[\eta]=a_{1}$, is the zero concentration limit of the relative viscosity.

For a properly designed capillary viscometer, the solution viscosity is almost proportional to the product of the solution density, $\rho(\mathrm{c})$, and the measured flow time, $t(\mathrm{c})$. The deviation from proportionality is due to a combination of kinetic energy effects and hydrodynamic effects at the end of the capillary. The manufacturer of the viscometer gives tables to correct the measured times for each of the viscometers. These corrections, designated by the manufacturer as the Hagenbach correction [12], are approximately of the form $1 / \mathrm{t}_{\mathrm{m}}{ }^{2}$, where $\mathrm{t}_{\mathrm{m}}$ is the measured time. The manufacturer's corrections were fitted to this form to interpolate their correction data. This correction is applied to each average flow time for solvent or solution yielding $t(c)$ where the $c$ refers to the concentration of the solution being measured.

From eq. 2 then

$$
K \rho(c) t(c)=K \rho(c) t(0)\left(1+a_{1} c+a_{2} c^{2}+\ldots\right)
$$

where the solvent viscosity is

$$
\eta(0)=K \rho(0) t(0)
$$

and where $\mathrm{K}$ is the viscometer constant.

Finally, we do not need to know $\mathrm{K}$ since the quantity of interest is the limiting value of

$$
[\eta]=(\eta(c)-\eta(0)) /(\eta(0) c)=a_{1}
$$

Thus, we may rewrite eq. 4 as

$$
\rho(c) t(c)=\rho(0) t(0)\left(1+a_{1} c+a_{2} c^{2} \ldots\right)
$$

On any given day measurements on only one concentration and related solvents, as described above, were practical. As viscometers became dirty, they were taken out of service and similar, but not identical, clean ones used in their place. Thus, the ratio, $T(\mathrm{c})$, is expected to be invariant at any concentration where $\mathrm{T}(\mathrm{c})$ is

$$
T(c)=(\rho(c) t(c)-\rho(0) t(0)) /(\rho(0) t(0))
$$

Following the normal definition of $[\eta]$ as the zero concentration limit of $T(c) / c$, we fit $T(c) / c$ to 
the expression

$$
T(c) / c=a_{1}+a_{2} c .
$$

The value of $\mathrm{a}_{1}$ so obtained was $157.8 \mathrm{~mL} / \mathrm{g}$ with a standard deviation of $1.8 \mathrm{~mL} / \mathrm{g}$. For our study of uncertainty, we consider the value of the standard deviation of the intercept reported above to be the expanded uncertainty in the repeatability of the measurement. This is reported in Table 1 with other contributions to the reported uncertainty of this measurement.

The coefficient $a_{2}$ is related to the Huggins constant [13] as

$$
\mathrm{k}_{\mathrm{H}}=\mathrm{a}_{2} /\left(\mathrm{a}_{1}\right)^{2} \text {. }
$$

From the fit we obtain the value of $\mathrm{k}_{\mathrm{H}}$ of $0.36 \mathrm{~g} / \mathrm{mL}$ with a standard deviation of the term of the fit of $0.12 \mathrm{~g} / \mathrm{mL}$.

Earlier, Wagner and Verdier [11] studied other fractions of the same base material, SRM 1475, certified as SRM 1482, SRM 1483, and SRM 1484. They measured and reported intrinsic viscosities in TCB on these materials. Fitting their data for the intrinsic viscosities, [ $\eta$ ], of SRM 1482, SRM 1483, and SRM 1484, we obtain

$$
\ln _{\mathfrak{e}}\left\{[\eta]_{\mathrm{w}}\right\}=0.7312 \ln _{\mathrm{e}}\left\{\mathrm{M}_{\mathrm{w}}\right\}-3.247
$$

where $[\eta]_{\mathrm{w}}$ is their measured intrinsic viscosity.

Using the $M_{w}$ of our polymer obtained in Section 5, we estimate a [ $\left.\eta\right]_{w}$ from Eq. 11 for SRM 2886 of $159 \mathrm{~mL} / \mathrm{g}$, in good agreement with our measured value. Furthermore, interpolating their $\mathrm{k}_{\mathrm{H}}$, we estimate their $\mathrm{k}_{\mathrm{H}}$ for this molecular mass as $0.45 \mathrm{~g} / \mathrm{mL}$, again in good agreement with our value.

\subsection{Estimating Uncertainties in the Intrinsic Viscosity Measurement}

The likely sources of uncertainty are discussed in the following subsections and the table referred to herein. For this analysis, we largely follow the paper of Wagner and Verdier [11].

\subsubsection{Shear Rate Dependence of Viscosity}

Low molecular mass polymers in dilute solution are expected to show little, or no shear rate dependence. Wagner and Verdier [2] were unable to detect shear rate dependence, even for SRM 1484 , a linear polyethylene with an $M_{w}$ of $114,000 \mathrm{~g} / \mathrm{mol}$. The capillary in their viscometer had a smaller diameter than that in the Schotte-Gerate viscometer we are using. Thus, we expect no shear rate dependence of the intrinsic viscosity of SRM 2886, which has a lower mass average 
molecular mass than SRM 1484. We assume the uncertainty introduced in the intrinsic viscosity by disregarding this contribution is zero.

\subsubsection{Solution Concentration and Density}

According to Wagner and Verdier [11], their reported value of $\rho(0)$ has an estimated relative expanded uncertainty of $0.2 \%$ and their reported value of the specific volume of the polymer in solution, $v_{a v g}$, has an expanded uncertainty of $0.04 \mathrm{~mL} / \mathrm{g}$. We used their values $\rho(0)$ and $v_{\text {avg }}$ in our calculations. The solvent density uncertainty leads to $0.4 \mathrm{~mL} / \mathrm{g}$ expanded uncertainty in intrinsic viscosity and the $\mathrm{v}_{\text {avg }}$ uncertainty Wagner and Verdier report leads to $0.04 \mathrm{~mL} / \mathrm{g}$ expanded uncertainty in intrinsic viscosity (see Section 4.3.3). Wagner and Verdier [11] estimated a relative uncertainty $0.03 \%$ in intrinsic viscosity due to the disregard of the buoyancy correction. Since we corrected for buoyancy, we take this uncertainty to be less than $0.01 \%$, or negligible.

All solutions but one were prepared so that at least $25 \mathrm{mg}$ of SRM 2886 was used. For the remaining solution, $15 \mathrm{mg}$ of SRM 2886 was used. We estimated that the balance used for this measurement had an expanded uncertainty of less than $0.1 \mathrm{mg}$. For those solutions where at least $25 \mathrm{mg}$ was used, we estimate a $0.1 \mathrm{mg}$ expanded uncertainty due to weighing would lead to an expanded uncertainty of $0.7 \mathrm{~mL} / \mathrm{g}$. For that solution where $15 \mathrm{mg}$ was used, we estimate a $0.1 \mathrm{mg}$ expanded uncertainty in weighing would lead to an expanded uncertainty of $1.0 \mathrm{~mL} / \mathrm{g}$. We take for the overall data that the uncertainty of a consistent $0.1 \mathrm{mg}$ change in the mass would lead to an expanded uncertainty of $0.8 \mathrm{~mL} / \mathrm{g}$ in intrinsic viscosity.

Solvent masses were measured with an expanded uncertainty of $0.01 \mathrm{~g}$. A minimum of $30 \mathrm{~g}$ of solvent was used. This uncertainty had negligible effect on the results and so was taken to be zero.

\subsubsection{Specific Volume of the Polymer}

The intrinsic viscosity, $[\eta]$, is the limit of

$$
[\eta]=L\{(\rho(c) t(c)-\rho(0) t(0)) /(\rho(0) t(0) c)\}
$$

where $L\{\}$ is taken to mean the limit at zero concentration. Following Wagner and Verdier [11] using the fact that the limit of the product is the product of the limit, they find

$$
\left.[\eta]=\rho(0)^{-1}\left(1+2 K^{1} / t_{m}(0)^{+3}\right) /\left(1-K^{\prime} / t_{m}(0)^{+3}\right) * L_{\{}\left(t_{m}(c)-t_{m}(0)\right) /\left(t_{m}(0) w\right)\right\}+\rho(0)^{-1}-v_{\text {avg }}
$$

where $\mathrm{w}$ is the mass fraction of solute in the solution and $\mathrm{K}^{\prime}$ is the kinetic energy term derived 
from corrections given by the viscometer manufacturer [12].

This formula corrects a typographical error in their formula 11. The formula shows that the intrinsic viscosity as made up of two terms if we disregard the kinetic energy ( $\mathrm{KE}$ ) corrections of the viscometer. Assuming these KE corrections are zero, we get then

$$
[\eta]=\rho(0)^{-1} L\left\{\left(\mathrm{t}_{\mathrm{m}}(\mathrm{c})-\mathrm{t}_{\mathrm{m}}(0)\right) /\left(\mathrm{t}_{\mathrm{m}}(0) \mathrm{w}\right)\right\}+\rho(0)^{-1}-\mathrm{v}_{\mathrm{avg}}
$$

The last two terms are the difference between the specific volume of the solvent, $\rho(0)^{-1}$, and the specific volume of the polymer in solution, $\mathrm{v}_{\mathrm{avg}}$. This difference is small, about a few tenths of an $\mathrm{mL} / \mathrm{g}$, compared to an overall intrinsic viscosity of about $157 \mathrm{~mL} / \mathrm{g}$ for this polymer. Since $\mathrm{v}_{\mathrm{avg}}$ was determined on other fractions of this polymer previously $[10,11]$, we estimate that our value of $v_{\text {avg }}$ has an uncertainty of no more than $0.04 \mathrm{~mL} / \mathrm{g}$. Thus, we take $0.04 \mathrm{~mL} / \mathrm{g}$ to be the uncertainty in intrinsic viscosity from this contribution.

\subsubsection{Timer Uncertainties}

Individual flow times were recorded to $0.01 \mathrm{~s}$. We take this to be the expanded uncertainty of the timer measurements. Since the intrinsic viscosity is the ratio of the time differences over a time, only the uncertainty in the time in the denominator is important. Since total flow times were between $40 \mathrm{~s}$ and $60 \mathrm{~s}$, a $0.01 \mathrm{~s}$ timer uncertainty would cause an expanded uncertainty of no more than $0.1 \mathrm{~mL} / \mathrm{g}$.

\subsubsection{Kinetic Energy or Hagenbach Corrections}

As noted above, kinetic energy, or Hagenbach, corrections were estimated from tables given by the viscometer manufacturer [12] and obey a $\mathrm{G} / \mathrm{t}(\mathrm{c})^{2}$ law. The value of $\mathrm{G}$ estimated from the manufacturer's table is $412 \mathrm{~s}^{3}$ for our viscometer. We take our value of $\mathrm{G}$ to have a relative expanded uncertainty of $20 \%$, twice that assumed by Wagner and Verdier [11] for their value of G. This leads to an expanded uncertainty of $0.3 \mathrm{~mL} / \mathrm{g}$ in the intrinsic viscosity of SRM 2886.

\subsubsection{Uncertainties Arising from Temperature Uncertainties}

Wagner and Verdier [11] estimate the relative temperature dependence of the intrinsic viscosity of polyethylene to be no more than $0.2 \% /{ }^{\circ} \mathrm{C}$ for polyethylene in theta solvents. The temperature dependence is expected to be less in TCB, which is a good solvent for polyethylene. Following Wagner and Verdier, we take $1 \% /{ }^{\circ} \mathrm{C}$ as the outside limit of the temperature dependence of intrinsic viscosity. We believe the Schott-Gerate constant temperature bath controls the temperature much better than $0.3^{\circ} \mathrm{C}$, including effects of temperature gradients. This conclusion arises partly because we have a reproducibility of better than $0.10 \mathrm{~s}$ out of about $41 \mathrm{~s}$ for the 
solvent flow times taken over a period of weeks. Further, we found a $1{ }^{\circ} \mathrm{C}$ change in temperature altered the measured flow time of the solvent by $0.32 \mathrm{~s}$. Thus, we take $0.5 \mathrm{~mL} / \mathrm{g}$ as the expanded uncertainty from the temperature.

\subsubsection{Estimated Combined Expanded Uncertainty}

In Table 1, the estimated expanded uncertainties from all sources are listed. Following NIST guidelines [14], we obtain the combined expanded uncertainties as the root sum of squares of these quantities.

\subsection{Determination of $M_{w}$ of SRM 2886 by Light Scattering}

\subsection{Solvent Preparation for Light Scattering and for Specific Refractive Index Increment}

The light scattering solvent, 1-chloronaphthalene, was purchased from Aldrich Chemical (Aldrich Chemical 18,575-2). According to the supplier, this 1-chloronaphthalene was $90 \%$ pure with 2chloronaphthalene as the only detectable impurity. A two-step purification method, described in Appendix II, involved crystallizing out the 2 -chloronaphthalene followed by vacuum distillation of the 1-chloronaphthalene.

The antioxidant Santonox, 3-tert-Butyl-4-hydroxy-2-methylphenyl sulfide (Aldrich Chemical, Milwaukee, WI), was added to the purified 1-chloronaphthalene in order to protect the polyethylene from oxidative degradation during the high temperature light scattering experiments and differential refractive index determinations. The antioxidant was dissolved in the 1chloronaphthalene at a concentration of $0.1 \mathrm{~g} / \mathrm{L}$ at $130^{\circ} \mathrm{C}$.

The 1-chloronaphthalene was sparged with dry nitrogen gas for a few hours immediately before adding solvent to polymer samples in preparing solutions to conduct experiments. The nitrogen sparging was used to minimize residual oxygen content in the solvent.

Solvent recovered from light scattering experiments was recycled. After the solutions had been allowed to cool and the polymer had separated out, the recovered material was drained through a filter. The collected solvent was redistilled by the process described in Appendix II. Since the 2chloronaphthalene impurity had already been removed exhaustively from such recovered solvent earlier, the preparatory refluxing process to remove the isomer was omitted.

5.2 Determination of Specific Refractive Index Increment 


\subsubsection{Instrumentation}

The specific refractive index increment ( $\mathrm{dn} / \mathrm{dc})$ for SRM 2886 was determined using a Chromatix KMX-16 (Thermo-Separation Products, Sunnyvale, CA) differential refractometer. The refractometer light source was a helium-neon (He-Ne) laser operating at a wavelength of 632.8 $\mathrm{nm}$. For room temperature calibration, the measurement cell was controlled at $25^{\circ} \mathrm{C}$. The measurement cell was heated to $130^{\circ} \mathrm{C}$ for the solution and solvent measurements.

\subsubsection{Calibration of Instrument at Room Temperature}

The differential refractometer was calibrated with aqueous $\mathrm{NaCl}$ solutions at $25^{\circ} \mathrm{C}$. Refractive increments versus concentration for several aqueous electrolyte solutions at several wavelengths of light had been reported by Kruis [15]. Refractive increments for the same solutions at the He-Ne laser wavelength, $632.8 \mathrm{~nm}$, have been determined from interpolation of the data in the Kruis tables $[15,16]$. A cubic equation for these refractive increments as a function of $\mathrm{NaCl}$ concentration in aqueous solution at $25^{\circ} \mathrm{C}$ is given in the instrument manual, and was used to compute the refractive increments of the aqueous $\mathrm{NaCl}$ solutions prepared as standards for calibrating the differential refractometer.

Analytical reagent $\mathrm{NaCl}$ (Baker and Adamson, Allied Chemical and Dye Corp, New York, NY) was dried in a hot air oven for approximately $18 \mathrm{~h}$ at a temperature of $140{ }^{\circ} \mathrm{C}$ in preparation to be used as a calibrant. Distilled water was degassed by boiling and left to cool to ambient temperature overnight in storage bottles tightly capped with zero headspace. The storage bottles had been leached out with several changes of boiling distilled water before being used to contain the degassed distilled water. Both salt and water components of each solution were measured gravimetrically, and atmospheric buoyancy corrections were applied to compute the concentrations as $\mathrm{g} \mathrm{NaCl} / 100 \mathrm{~g} \mathrm{H}_{2} \mathrm{O}$.

Following instructions in the instrument instruction manual [17], calibration measurements for the differential refractometer were conducted on four $\mathrm{NaCl}$ solutions ranging in concentration from $0.5 \mathrm{~g} \mathrm{NaCl} / 100 \mathrm{~g} \mathrm{H}_{2} \mathrm{O}$ to $2.0 \mathrm{~g} \mathrm{NaCl}_{1} 100 \mathrm{~g} \mathrm{H}_{2} \mathrm{O}$ in intervals of $0.5 \mathrm{~g} \mathrm{NaCl} / 100 \mathrm{~g} \mathrm{H}_{2} \mathrm{O}$. The calculated refractive increments of the solutions were fitted to their average image displacements to generate a linear calibration equation of refractive increment versus image displacement, $\mathrm{dn} / \mathrm{dc}$. The instrument calibration was found to be insignificantly changed from calibrations made many years earlier indicating that we were simply verifying an earlier calibration. In fact, the plot of the calibration verification points, when overlaid on an earlier instrument calibration plot, produced a graph in which the two data sets were indistinguishable.

\subsubsection{Solution Preparation and Handling}

Polymer solutions were prepared using 1-chloronaphthalene solvents with a mass fraction of 0.01 $\%$ Santonox (Aldrich, Milwaukee, WI) antioxidant. The 1-chloronaphthalene (Aldrich, 
Milwaukee, WI) was purified by distillation before use as described in Appendix II. Solution concentrations in ranges described in section 5.2.4 were made directly by weighing, without employing successive dilution techniques. Concentrations were calculated from densities and partial specific volumes determined earlier in this laboratory [10]. A general-purpose laboratory convection oven set at a temperature of approximately $145^{\circ} \mathrm{C}$ was used to dissolve the polymer solutions. Glass bottles with ground glass necks and caps were used as dissolution vessels for the polymer samples. Experiments conducted earlier (private communication, R.C. Christensen) demonstrated that solvent loss at $130^{\circ} \mathrm{C}$ through the ground glass joint was negligible.

Transfer of the polymer solutions from the glass dissolution vessels into the refractometer measurement cell was accomplished with a specially constructed glass funnel/valve assembly heated to approximately $145^{\circ} \mathrm{C}$. A $6.8 \mathrm{~cm}$ diameter Pyrex glass powder funnel was modified by having the barrel of a $5 \mathrm{~mL}$ glass luer lock syringe attached to the funnel stem. An on-off valve (Popper \& Sons, Inc., New Hyde Park, NY) was attached to the luer fitting and a shortened 20gage needle was attached to the valve. The funnel was placed in a heating mantle (Glas-Col, Terre Haute, IN) and a flexible electric heating tape (Barnstead/Thermolyne, Dubuque, IA) was wrapped around the stem, valve and needle that protruded below the heating mantle. The funnel assembly was supported by a three-jaw clamp attached to the funnel stem and an adjustable height rack and pinion post (Edmund Industrial Optics, Barrington, NJ). The rack and pinion post was lowered to position the needle in the sample cell for filling the cell with polymer solution and raised above the cell to provide access to the cell by suction tubing, which was used to empty the cell. Heating mantle and heat tape temperature were measured with a digital thermocouple thermometer (John Fluke Mfg. Co., Palatine, IL) and adjusted by Variac autotransformers (General Radio Co., Cambridge, MA). Dissolved polymer solutions were removed from the oven and poured from the dissolution bottle into the heated funnel. Using the on-off valve on the funnel stem, the refractometer measurement cell was filled with hot polymer solution. Following the instrument instruction manual [17], the cell was filled and emptied five times before measurements were made on the solution.

\subsubsection{Measurement of $(\mathrm{dn} / \mathrm{dc})$ at $130^{\circ} \mathrm{C}$}

Refractive index increments between solvent and solutions of polyethylene in 1-chloronaphthalene were determined on solutions that had been prepared on the morning of the day the measurements were made. Five solutions with concentrations between $3.0 \mathrm{~g} / \mathrm{L}$ to $14.0 \mathrm{~g} / \mathrm{L}$ of SRM 2886 were prepared by the procedure describe in Section 5.2.2. For each solution two repeated image displacement measurements were conducted on these solutions of SRM 2886 following methods as outlined in KMX 16 manual. Solvent-versus-solvent measurements were made before and after each solution-versus-solvent measurement. The incremental image displacement by each solution was obtained by subtracting the mean of the bracketing solvent average image displacements from the average image displacement by the solution. The refractive index increment of each solution was computed by application of the calibration equation to the incremental image displacement of the solution. The specific refractive index increments were obtained by dividing the refractive index by the concentration of 
the solution. The average value of the specific refractive index increment of the solutions was found to be, $\mathrm{dn} / \mathrm{dc}=-0.1834 \mathrm{~mL} / \mathrm{g}$, for SRM 2886 in 1-chloronaphthalene at $130^{\circ} \mathrm{C}$ with a standard deviation of $0.0025 \mathrm{~mL} / \mathrm{g}$. This issue of uncertainty and fit of this measurement will be discussed in section 5.10.3.

Previous reports of the differential refractive index at $632.8 \mathrm{~nm}$ for other comparable polyethylenes in 1-chloronaphthalene gave values ranging from $-0.178 \mathrm{~mL} / \mathrm{g}$ to $-0.183 \mathrm{~mL} / \mathrm{g}$ at $135^{\circ} \mathrm{C}[18-20]$. Our mean value is at the limit of these reported values, but well within the range of values considering our expected uncertainty.

\subsection{Refractive Indices of Solvent and Calibrant}

The primary standard for this measurement is benzene; other standards are derived from it. The refractive index of the benzene primary standard at $23{ }^{\circ} \mathrm{C}$ and $632.8 \mathrm{~nm}$ is taken to be 1.4941 [11].

G. B. Arrowsmith, G. H. Jeffrey, and A. I. Vogel [23] tabulated the refractive index at the Sodium D line $n_{D}=1.63315$ at $20^{\circ} \mathrm{C}$ and a density at $20^{\circ} \mathrm{C}$ of $1.1932 \mathrm{~g} / \mathrm{mL}$ for 1 -chloronaphthalene. Christensen [10] reports the density of 1 -chloronaphthalene as $1.098 \mathrm{~g} / \mathrm{cm}^{3}$ at $130^{\circ} \mathrm{C}$ and Wagner [24] reports the density of 1 -chloronaphthalene as $1.098 \mathrm{~g} / \mathrm{cm}^{3}$ at $135^{\circ} \mathrm{C}$. The Lorentz-Lorenz molar refraction relation is used to estimate the refractive index for 1-chloronaphthalene at $130{ }^{\circ} \mathrm{C}$ from the densities at $20^{\circ} \mathrm{C}$ and $130{ }^{\circ} \mathrm{C}$ and the refractive index at $20^{\circ} \mathrm{C}$. Since the refractive index of 1-chloronaphthalene at $130^{\circ} \mathrm{C}, \mathrm{n}_{\mathrm{D}}=1.5772$, is only used in the reflection correction to the $\mathrm{M}_{\mathrm{w}}$ the limited accuracy of this value is acceptable.

Dow Corning 705 silicone oil is used as the vat fluid. The Lorentz-Lorenz molar refraction relation was applied to the refractive index at $632.8 \mathrm{~nm}$ at $25^{\circ} \mathrm{C}$, and the density at various temperatures (Dow technical consultant Gary McIntyre) to estimate the refractive index of the Dow Corning 705 silicone oil at $130{ }^{\circ} \mathrm{C}$ as $n_{D}=1.516$. Since the refractive index of Dow Corning 705 silicone oil at $130{ }^{\circ} \mathrm{C}$ is only used in the reflection correction to the $\mathrm{M}_{\mathrm{w}}$, the limited accuracy of this value is acceptable.

\subsection{Design of Light Scattering Instrument}

Dr. Charles Han of the NIST Polymers Division designed and constructed the light scattering apparatus. We review here some of the details of the instrument. A Universal circular dividing table (Universal Vise \& Tool Co.), with a center bore design, is used as the goniometer. This goniometer is mounted on a rigid optical table (Newport Research Corporation). A beam of vertically polarized incident light (wavelength $=632.8 \mathrm{~nm}$ ) is provided by a $10 \mathrm{~mW} \mathrm{He}-\mathrm{Ne}$ laser (Melles-Griot) also mounted.

The goniometric axis is defined by the center of the goniometer and aligned with a tapered center 
bore in the goniometer. The vat housing, which contains the sample cell, is mounted on an aligning rod with a precision-machined taper to engage the complementary taper of the center bore of the goniometer. The receptacle hole for the sample cell is machined at the cylindrical axis in the top flange plate of the vat housing. By this arrangement the center axis of the cylindrical cell and the vat housing are held coincident with the goniometric axis. The intensity of light scattered at varied angles from the sample cell is measured by a photomultiplier in the receiving optics mounted on a rigid beam attached to the goniometer.

The vat is thermostatted by a copper cylinder, which is built onto the underside of the vat housing cover plate, and extends down into the vat fluid. The vat temperature is controlled and indicated by a PID temperature controlling system, a copper constant current supplier, a four wire RTD and a voltage comparitor. The controlling system receives a voltage imbalance signal from a fourwired platinum resistance temperature probe in the thermostatting cylinder and the voltage comparitor, and sends energy to cartridge heaters in the thermostatting cylinder. When working at high temperatures, significant thermal gradients can develop inside the vat between the thermostatting cylinder and the peripheral region of the vat. Such thermal gradients were repressed by applying a flexible heating mantle to the external cylindrical surface of the vat housing, and controlling the mantle temperature at a few degrees Celsius below the experimental temperature. The mantle was specially constructed for this apparatus, and the control provided by HPS Division, MKS Instrument, Inc. (MKS Instrument, Inc, 5330 Sterling Drive, Boulder, CO 80301).

Light scattering cells were fabricated from precision ground and polished glass tubing to uniform wall thickness (Wilmad Glass Co.), with both inside and outside cylindrical surfaces polished. The tubing is of $33 \mathrm{~mm}$ outside diameter and has a refractive index $\mathrm{n}_{\mathrm{D}}=1.50$.

\subsection{Instrument Calibration Protocol at $130^{\circ} \mathrm{C}$}

1,2,4-trichlorobenzene (TCB) (Aldrich Chemical high purity, Milwaukee, WI) was employed as the working light scattering calibration standard at $130^{\circ} \mathrm{C}$. The calibration of TCB as the working standard is traced to the Rayleigh ratio $\left(\mathrm{R}_{\mathrm{V}}\right)$ of benzene at ambient temperature $\left(23^{\circ} \mathrm{C}\right)$ in vertically polarized incident light of $632.8 \mathrm{~nm}$ wavelength, determined by Kaye \& McDaniel [25].

First, a Durasil optical glass rod was calibrated by comparing its scattering intensity at a $90^{\circ}$ angle with that of a benzene cell at the same angle, with the glass rod and benzene cell both at $21^{\circ} \mathrm{C}$. Then the vat temperature was increased to $130^{\circ} \mathrm{C}$ in which environment three TCB cells were calibrated by comparison of their scattering intensities with that of the glass rod. The effective $R_{V}$ of the glass rod is assumed to be invariant with temperature in this range. However, relating the scattering intensity measurements at the two temperatures requires conservation of the optical alignment with change in temperature. The only significant disturbance in the optical alignment results from the change in refractive index of the vat fluid with change in temperature. This problem was solved by conducting the measurements at $21{ }^{\circ} \mathrm{C}$ with the vat filled with anisole 
which has $n_{D}=1.5160$ at $20^{\circ} \mathrm{C}$, and conducting the measurements at $130{ }^{\circ} \mathrm{C}$ with the vat filled with Dow Corning 705 silicone oil which has $n_{D}=1.516$ at that temperature.

The scattering intensities at $90^{\circ}$ angle $\left(\mathrm{I}_{90}\right)$ of the benzene standard cell and the glass rod standard were measured alternately at $21^{\circ} \mathrm{C}$. A total of 40 such pairs of measurements were conducted over an interval of two days. The resulting population of experimentally determined scattering intensity ratios yielded an average $\left[\mathrm{I}_{90}(\mathrm{GLASS}) / \mathrm{I}_{90}(\mathrm{BENZENE})\right]$ with a relative standard uncertainty of $1.16 \%$.

A series of TCB standard cells was prepared by filtering high purity TCB into each cell through a double layer of Millipore cellulose acetate-nitrate membrane with $0.2 \mu \mathrm{m}$ pore size. Filtration of TCB into the cells was conducted at ambient temperature. It was found that a TCB sample could be maintained at the experimental temperature $\left(130^{\circ} \mathrm{C}\right)$ and slightly higher for at least two days without detectable change. A new TCB standard cell was prepared for use with each set of solutions during the characterization of this polymer by light scattering. The $\mathrm{I}_{90}$ of the glass rod standard was compared with the $I_{90}$ of each of three TCB cells at $130^{\circ} \mathrm{C}$. The $I_{90}$ values of the glass rod and the TCB cell were measured alternately. A total of 14 pairs of such $\mathrm{I}_{90}$ measurements were conducted with the glass rod and each of the TCB cells, resulting in three average values for the ratio $\left[\mathrm{I}_{90}(\mathrm{TCB}) / \mathrm{I}_{90}(\mathrm{GLASS})\right]$ in very close agreement. The three determinations resulted in a single average value for the ratio with a relative standard uncertainty of $0.2 \%$.

As small error was introduced because we measured the ratio of scattering from benzene to the glass cell, $\mathrm{S}$, at $21{ }^{\circ} \mathrm{C}$ not at $23{ }^{\circ} \mathrm{C}$ where the $\mathrm{R}_{\mathrm{v}}$ was measured by Kaye and McDaniel [25]. Ehl, Loucheux, Reiss, and Beniot [26] have measured this temperature variation. Our measurements of $\mathrm{S}$ give us $\mathrm{S}_{21}$, the $\mathrm{S}$ at $21^{\circ} \mathrm{C}$. We need $\mathrm{S}_{23}$, the ratio measured with benzene and the glass rod at $23{ }^{\circ} \mathrm{C}$. From Ehl, Loucheux, Reiss and Beniot [26] we estimate

$$
\mathrm{S}_{23}=0.9946 \mathrm{~S}_{21}
$$

As noted earlier, Kaye and McDaniel [25] determined the value $\mathrm{R}_{V}=12.63 \times 10^{-6}$ for benzene under these optical conditions, with a standard uncertainty of $0.21 \times 10^{-6}$. The product of ratios, $\left[\mathrm{I}_{90}(\mathrm{GLASS}) / \mathrm{I}_{90}(\mathrm{BENZENE})\right]$ and $\left[\mathrm{I}_{90}(\mathrm{TCB}) / \mathrm{I}_{90}(\mathrm{GLASS})\right]$ gave a value of $\mathrm{S}_{21}$. This was applied to the $R_{V}$ for benzene by Kaye and McDaniel to estimated working value of $R_{V}=35.6 \times 10^{-6}$ for the $\mathrm{TCB}$ at $130^{\circ} \mathrm{C}$ in vertically polarized incident light of $632.8 \mathrm{~nm}$ wavelength. The standard uncertainty for this value of $S_{21}$ is computed as the root sum of squares of the standard uncertainties of the two ratios.

This method of calibration was tested by using TCB as the working standard in light scattering experiments to determine the molecular mass $\left(M_{w}\right)$ of the polyethylene standard, SRM 1483. The resulting $\mathrm{M}_{\mathrm{w}}$ from these experiments conducted with TCB as the calibrating standard were statistically indistinguishable from the certificate value of the $\mathrm{M}_{\mathrm{w}}$ for SRM 1483 [2]. 


\subsection{Solution Preparation}

SRM 2886 samples from the SRMP vials were weighed on an OHAUS GA200D analytical electrobalance (Ohaus Corp., Florham Park, NJ), with $0.0001 \mathrm{~g}$ resolution, and transferred to sample bottles. All polymer samples weighed $30 \mathrm{mg}$ or greater in order to repress relative uncertainty in the sample mass. The 1-chloronaphthalene was sparged for $2 \mathrm{~h}$ with dry $\mathrm{N}_{2}$ gas. The sparged solvent was then measured into bottles containing the polymer samples, plus two empty bottles to contain solvent samples. The solvent mass was determined by mass difference on a Mettler PE 3600 electrobalance (Mettler Toledo, Columbus, OH). Atmospheric buoyancy corrections and densities of solvent and polymer were applied to calculate absolute solution concentrations at the experimental temperature. Both balances were checked during the certification period often by a NIST calibrated $50 \mathrm{mg}$ mass for the Ohaus balance and a NIST calibrated $50 \mathrm{~g}$ mass for the Mettler. The balances read with accuracy to the last reading value.

Solution concentrations in range described in Section 5.9 were made directly by weighing, without employing successive dilution techniques. Concentrations were calculated from densities and partial specific volumes determined earlier in this laboratory [10]. The bottles were capped with ground glass tops and placed in an oven at about $150{ }^{\circ} \mathrm{C}$. They were heated and agitated occasionally for about $2 \mathrm{~h}$ before commencing filtration.

The syringe filter assembly used was a $25 \mathrm{~mm}$ diameter stainless steel Swinny type (Millipore Corp., Bedford, MA). The Swinny filter was attached to a glass syringe modified by adding a spherical joint at the top end, to provide connection to a dry nitrogen source used to apply an inert low-pressure gas to propel solution through the filter at a realistic rate. Each Swinny was assembled with a double layer of Pall-Gelman Sciences ZEFLUOR all-Teflon filtering membrane with $0.5 \mu \mathrm{m}$ pore size (Pall Corp., Port Washington, NY). These filtering assemblies were heated to $150{ }^{\circ} \mathrm{C}$ in the oven along with the solvent and solution bottles.

After the polymer samples had dissolved to form clear homogeneous solutions, the solvent and solution samples were filtered into their respective light scattering cells.

The hot filtration was conducted in a thermostatted apparatus that maintained both cell and filtering assembly in the range $140{ }^{\circ} \mathrm{C}$ to $150^{\circ} \mathrm{C}$. The filtering assembly was heated in a vertical glass cylinder wrapped with a nichrome coil heating element. The cell was mounted in an aluminum block heater below.

After the solution sample was poured into the filtering assembly, and the low nitrogen gas pressure was applied, the first $\left(5\right.$ to10) $\mathrm{cm}^{3}$ filtrate was collected in a waste vial and discarded. The next approximately $20 \mathrm{~cm}^{3}$ filtrate was directed into the light scattering cell. The $\mathrm{N}_{2}$ gas pressure was adjusted to obtain a filtration flux of about 1 drop per few seconds to a few drops per second.

Subsequent light scattering measurements generally indicated a high success rate in obtaining solution and solvent samples free from dust contamination. At the conclusion of an experiment, 
the cell components and filtering assembly components were cleaned with refluxing hot xylene vapors. This cleaning process appeared successful in removing dust and polymer exhaustively.

\subsection{Measurement Protocol}

The temperature was controlled at $130.0^{\circ} \mathrm{C} \pm 0.2{ }^{\circ} \mathrm{C}$ in all light scattering measurements on polyethylene in 1-chloronaphthalene. In all experiments, the intensity measuring system was calibrated with the scattering intensity at $90^{\circ}$ angle (I(90)) by a TCB standard cell described above. The scattering intensity from the solvent and each solution was measured at eight angles in the range from $37.5^{\circ}$ to $135^{\circ}$. Scattering intensity measurements versus angle $(\mathrm{I}(\theta))$ were conducted with the solvent cell immediately following the calibration against TCB, and twice more after I $(\theta)$ measurements had been conducted on all the solution cells.

All cells containing the TCB secondary standard and samples of solvent or solution were stored in an oven at ( 140 to 150$){ }^{\circ} \mathrm{C}$. Each cell was transferred from the oven to the vat in preparation for scattering intensity measurements, and allowed to remain undisturbed in the vat for at least 10 min to equilibrate at the experimental temperature before initiating the measurements.

At the conclusion of each experiment, the TCB secondary standard cell was withdrawn from the oven and stored at ambient temperature. In two cases replicate light scattering experiments were conducted with a set of solution and solvent samples on the day following the initial experiment, after the polyethylene had been in hot solution environment for longer than $24 \mathrm{~h}$. The TCB secondary standard cell was returned to the oven a few hours before initiating the replicate experiment in order to heat it up to the range of experimental temperature. These replicate experiments gave results, which appeared to indicate thermal stability of this polymer in its high temperature solution state over an interval of at least $24 \mathrm{~h}$.

\subsection{Analysis of Light Scattering Data}

Light scattering data from polymer solutions of concentration $\mathrm{c}$ and scattering angle $\Theta$ may be analyzed by fitting the scattering signal $\mathrm{I}(\Theta, \mathrm{c})$ to $[27]$

$$
I(\Theta, c)=I(\Theta, 0)+c I_{G} /\left\{(\sin \Theta) \sum_{i j} C_{i j} c^{i} \sin ^{2 j}(\Theta / 2)\right\} .
$$

In eq. (5), $I_{G}$ is the scattering signal from the TCB working standard at $\Theta=90^{\circ}$.

We must first decide how many terms on the right-hand side of eq. (15) need to be included to provide an adequate fit to the experimental data. The dependence of $c / I_{c}$, where $I_{c}=\sin \Theta[I(\Theta, c)-$ $\mathrm{I}(\Theta, 0)] / \mathrm{I}_{\mathrm{G}}$, upon $\mathrm{c}$ and upon $\sin ^{2}(\Theta / 2)$ reflects solute-solvent interactions and solute size, respectively. Accordingly, preliminary scattering data for SRM 2886 were first analyzed as $c / I_{c}$ 
versus $\sin ^{2}(\Theta / 2)$ and $c$ and $c^{2}$, to see whether a linear expansion (i.e., retaining only $C_{00}, C_{01}$, and $\mathrm{C}_{10}$ ) would provide an adequate fit. The analysis revealed that the linear approximation was adequate at concentrations below $5 \mathrm{~g} / \mathrm{L}$ for SRM 2886 (see Section 5.10 .13 for a more complete discussion).

Thus, we used for the final analysis

$$
\mathrm{I}(\Theta, \mathrm{c})=\mathrm{I}(\Theta, 0)+\mathrm{cI} \mathrm{I}_{\mathrm{G}} /\left\{\sin \Theta\left(\mathrm{C}_{00}+\mathrm{C}_{01} \sin ^{2}(\Theta / 2)+\mathrm{C}_{10} \mathrm{c}\right)\right\}
$$

The coefficients in eq. (16) are related to the $M_{w}$, molecular mean-square radius of gyration, $R_{G}{ }^{2}$, and the second viral coefficients, $A_{2}$, by $[27,28]$ :

$$
\begin{aligned}
& \mathrm{M}_{\mathrm{w}}=\left(\mathrm{K}^{\prime \prime} \mathrm{C}_{00}\right)^{-1} \\
& \mathrm{R}_{\mathrm{G}}{ }^{2}=3\left[\lambda_{0} /(4 \pi \mathrm{n})\right]^{2} \mathrm{C}_{01} / \mathrm{C}_{00} \\
& \mathrm{~A}_{2}=\mathrm{K}^{\prime \prime} \mathrm{C}_{10} / 2 \\
& \mathrm{~K}^{\prime \prime}=4 \pi^{2} \mathrm{n}_{\mathrm{B}}{ }^{2}(\mathrm{dn} / \mathrm{dc})^{2} /\left(\lambda_{0}{ }^{4} \mathrm{~N}_{\mathrm{A}} \mathrm{R}_{\mathrm{v}}{ }^{\mathrm{B}} \mathrm{S}_{23}\right)
\end{aligned}
$$

where:

$\lambda_{0}$ is the wavelength in vacuum of the scattered light, $632.8 \mathrm{~nm}$ in this work, $\mathrm{n}$ and $\mathrm{n}_{\mathrm{B}}$ are the indices of refraction of the solvent and benzene taken as 1.5772 and 1.510 at $23{ }^{\circ} \mathrm{C}$, respectively calculated as described in Section 5.3, dn/dc is the specific refractive index increment of the solution, measured as described in 5.2.4, $\mathrm{N}_{\mathrm{A}}$ is Avogadro's number, taken as $6.022 \times 10^{23} / \mathrm{mol}$, $\mathrm{R}_{\mathrm{v}}{ }^{\mathrm{B}}$ is the Rayleigh ratio for the total scattering of vertically polarized light from benzene at $23{ }^{\circ} \mathrm{C}$, used as the calibration standard. $\mathrm{S}_{23}$ is the ratio of the scattering of the benzene at $23{ }^{\circ} \mathrm{C}$ to the TCB working standard at $130^{\circ} \mathrm{C}$. The method of obtaining $\mathrm{S}_{23}$ is described in section 5.5.

Preliminary fitting was done in the Zimm form, that is, plots of $c / I_{c}$ versus $\sin ^{2}(\Theta / 2)$ and $c$, or if we wish to include third virial terms as $c / I_{c}$ versus $\sin ^{2}(\Theta / 2)$ and $c$ and $c^{2}$. In the Zimm form we found less than $1 \%$ relative change in the fitting parameters, particularly the molecular masses, between the fits including or excluding the $\mathrm{c}^{2}$ term. We then fit to the nonlinear form in eq 16 . This allows us to include the correct weighting of the data and also the zero concentration terms. Again we found only small changes in all fitting parameters between the fit to the Zimm form and the fit to the form of eq.16 even when we included $\mathrm{c}^{2}$ terms in the form of eq. 16.

\subsection{Results for SRM 2886}

Six sets of light scattering solutions were made from SRM 2886 using 1-chloronaphthalene as solvent. Each set consisted of three or four independently prepared solutions with concentrations from $(0.5$ to 4$) \mathrm{g} / \mathrm{L}$. One set had a solution concentration of $5 \mathrm{~g} / \mathrm{L}$. The polymer for each solution within each set was taken from the SRM sample vials or the division supply bottles. Intensities 
were measured at eight scattering angles in the range from $37.5^{\circ}$ to $135^{\circ}$. The intensities of scattered light in each set were fitted by least squares as explained above, and the results were used to calculate $M_{w}, A_{2}$ and $R_{g}$ using eqns (17)-(20). The values of $M_{w}, A_{2}$, and $R_{g}$ obtained from the six sample sets were then averaged. The resulting mean values and sample standard deviations are given in Table 2. Light scattering gave an $\mathrm{M}_{\mathrm{w}}$ of about $87.0 \times 10^{+3} \mathrm{~g} / \mathrm{mol}$ with a sample standard deviation of $2.2 \times 10^{+3} \mathrm{~g} / \mathrm{mol}$, a value of $\mathrm{A}_{2}$ of $0.00124 \mathrm{~mol} \mathrm{~mL} / \mathrm{g}^{2}$ with a sample standard deviation of $0.00007 \mathrm{~mol} \mathrm{~mL} / \mathrm{g}^{2}$ and a value of $\mathrm{R}_{\mathrm{g}}$ of $20.8 \mathrm{~nm}$ with a sample standard deviation of $1.8 \mathrm{~nm}$.

The value of $\mathrm{A}_{2}$ is in close agreement with that estimated by Han, Wagner and Verdier [27] in the previous certification of SRM 1482, SRM 1483 and SRM1484. They estimate $A_{2}=0.00109 \mathrm{~mol}$ $\mathrm{mL} / \mathrm{g}^{2}$ for SRM 1483 which has an $\mathrm{M}_{\mathrm{w}}=32.1 \times 10^{+3} \mathrm{~g} / \mathrm{mol}$ and $\mathrm{A}_{2}=0.00103 \mathrm{~mol} \mathrm{~mL} / \mathrm{g}^{2}$ for $\mathrm{SRM}$ 1484 with $\mathrm{M}_{\mathrm{w}}=119.6 \times 10^{+3} \mathrm{~g} / \mathrm{mol}$. Our value of $0.00124 \mathrm{~mol} \mathrm{~mL} / \mathrm{g}^{2}$ is close to these values considering our estimated uncertainty in $A_{2}$. They estimate $R_{g}=8.2 \mathrm{~nm}$ for $S R M 1483$ and $R_{g}=$ $21.7 \mathrm{~nm}$ for SRM 1484. For SRM1483, they consider the possibilities of large systematic uncertainties in $R_{g}$. We have the same problems with the $R_{g}$ we estimate. This is due to problem of alignment we find with our I $\sin (\Theta)$. Considering all these problems, our value of $20.8 \mathrm{~nm}$ is reasonably close to their values.

The standard deviation of the mean for the average $M_{w}$ of SRM 2886 is $1.1 \times 10^{+3} \mathrm{~g} / \mathrm{mol}$. In compliance with the NIST policy [14] on reporting uncertainties in measurement, the component uncertainty due to variance among the six $\mathrm{M}_{\mathrm{w}}$ determinations is computed as the standard deviation of the mean. Table 3 reports twice this value as the expanded uncertainty.

\subsection{Estimation of Uncertainties Due to Systematic Effects in the Light Scattering}

We list the likeliest sources of systematic uncertainty in the determination of $\mathrm{M}_{\mathrm{w}}$ by light scattering measurements described in the preceding sections, and attempt to estimate upper limits for their magnitudes. For this purpose, we employ a scheme similar to that used in ref. [27] for the estimation of systematic uncertainties in SRM's 1482, 1483 and 1484 and ref [29] on the recertification of SRM 706a. These uncertainties are listed in Table 3 for SRM 2886.

\subsubsection{Indices of Refraction}

Following Ref. [27], we estimate that $0.1 \%$ is a proper upper limit for systematic relative standard uncertainties in $\mathrm{M}_{\mathrm{w}}$ arising from uncertainties in the literature values of benzene index of refraction, the calibrating liquid.

\subsubsection{Calibration of the Differential Refractometer}

\subsubsection{Literature Values of $\mathrm{dn} / \mathrm{dc}$ for Aqueous $\mathrm{NaCl}$}


Calibration of the differential refractometer required interpolation of the data of Ref. $[15,16,17]$ to the $632.8 \mathrm{~nm}$ wavelength used in the light-scattering measurements. We estimate the relative standard uncertainty in the interpolated values of $\Delta \mathrm{n}$ as $0.6 \%$, due primarily to uncertainties in the interpolation process. The calibration factor determined for our differential refractometer had a relative standard deviation (rsd) of $0.097 \%$. Applying a coverage factor of 2 to this rsd yields a Type A expanded uncertainty of $0.19 \%$ for this measurand [14]. Combining this uncertainty with an allowance for possible linear uncertainties in the refractometer, we estimate that a proper upper limit for relative uncertainty in $\mathrm{dn} / \mathrm{dc}$ is $1 \%$. Considered as a 95 percent confidence interval estimate, this quoted uncertainty provides a expanded uncertainty in $\mathrm{dn} / \mathrm{dc}$ of $1 \%$ which would contribute a $2 \%$ or $1.7 \times 10^{+3} \mathrm{~g} / \mathrm{mol}$ expanded uncertainty in $\mathrm{M}_{\mathrm{w}}$ determination.

\subsubsection{Measured Value of dn/dc of SRM 2886}

The differential refractive index dn/dc of SRM 2886 in 1-chloronaphalene at a temperature of 130 ${ }^{\circ} \mathrm{C}$ was determined as described in Section 5.2.4. The mean value obtained for $\mathrm{dn} / \mathrm{dc}$ was $-0.1834 \mathrm{~mL} / \mathrm{g}$, with a standard deviation of $0.0025 \mathrm{~mL} / \mathrm{g}$. The uncertainty in the mean is then $0.0013 \mathrm{~mL} / \mathrm{g}$. We take the expanded uncertainty of this measurement as $0.0026 \mathrm{~mL} / \mathrm{g}$, or a relative uncertainty of $1.4 \%$.

There appears to be a small concentration drift in the data. This is mainly due to the highest concentration point. To check the effect of this drift, we refitted the data dropping the highest concentration and found a $\mathrm{dn} / \mathrm{dc}$ of $-0.1826 \mathrm{~mL} / \mathrm{g}$, a number well within our expected expanded uncertainty. Furthermore, an ANOVA of the data did not indicate the highest concentration $\mathrm{dn} / \mathrm{dc}$ to fall out of the error expected from the rest of the data. We therefore accept that we can average the data.

As the $\mathrm{dn} / \mathrm{dc}$ appears as the second power in the $\mathrm{M}_{\mathrm{w}}$ calculation, the uncertainty in the calculated $M_{w}$ that results from the uncertainty in the $\mathrm{dn} / \mathrm{dc}$ is estimated as twice the estimated relative expanded uncertainty in the $\mathrm{dn} / \mathrm{dc}$, or $2.8 \%$. This gives an expanded uncertainty in the $\mathrm{M}_{\mathrm{w}}$ of 2.5 $\times 10^{+3} \mathrm{~g} / \mathrm{mol}$.

Contributions to the uncertainty of the value of the density of the solvent to $\mathrm{dn} / \mathrm{dc}$ are discussed in section 5.10.8.

\subsubsection{Wavelength of Radiation}

For the He-Ne laser employed in this work, uncertainties in the wavelength of the radiation are completely negligible compared with uncertainties from other sources.

\subsubsection{Calibration Constant for Light Scattering}


The protocol for the calibration is described earlier. For each step, we estimate an uncertainty.

\subsubsection{Rayleigh Ratio of Benzene at Room Temperature}

For benzene at $632.8 \mathrm{~nm}$, Ref. [23] gives: $R_{V, V+H}=12.6_{3} \times 10^{-6} \mathrm{~cm}^{-1}$. We abbreviate $R_{V, V+H}$ by $R$. The authors of Ref. [23] apparently believed that their $\mathrm{R}$-values have a relative standard uncertainty of $<2 \%$ (all from systematic uncertainty). They quote a relative standard deviation for their R-value for benzene of $0.21 / 12.63$, or $1.7 \%$. This yields a relative expanded uncertainty of $3.9 \%$, or $3.4 \times 10^{+3} \mathrm{~g} / \mathrm{mol}$.

\section{10.5.2 Estimating Ratio of Benzene Scattering to Glass Rod Scattering at Room Temperature}

We have run 20 repeats of the measurements of the ratio of the scattering of the benzene calibrant to the scattering of the glass rod as described in Section 5.5. We take the uncertainty in the repeatability of this experiment as the overall uncertainty of the measurement. The relative standard deviation of this measurement is given as $1.2 \%$. The relative standard deviation of the mean is $0.27 \%$. We take $0.6 \%$, or $0.5 \times 10^{+3} \mathrm{~g} / \mathrm{mol}$, as the expanded uncertainty from the ratio of the benzene scattering to the glass rod scattering.

A small correction is introduced arising from the fact we calibrated our rod against benzene at $21{ }^{\circ} \mathrm{C}$ rather than benzene at $23^{\circ} \mathrm{C}$. We estimated that correction was 0.9946 from literature value on the temperature variation of the scattering from benzene [26]. We estimate from that work as a generous estimate of the relative expanded uncertainty from this calculation to be $0.2 \%$, or less than $0.1 \times 10^{+3} \mathrm{~g} / \mathrm{mol}$.

From both above corrections we take an expanded uncertainty from all these contributions to be $0.6 \times 10^{+3} \mathrm{~g} / \mathrm{mol}$.

\subsubsection{Temperature Dependence of Scattering of Glass Rod from $21{ }^{\circ} \mathrm{C}$ to $130^{\circ} \mathrm{C}$}

Han, Wagner and Verdier [27] discussed this issue in Section 4.1.3 of their paper on $\mathrm{M}_{\mathrm{w}}$ determinations of SRM 1482, SRM 1483, and SRM 1484. Since the uncertainty is in the calibration it appears as a percentage of the final result. In that paper, they concluded the maximum relative expanded uncertainty of assuming the scattering of the rod is unchanged from $23{ }^{\circ} \mathrm{C}$ to $130{ }^{\circ} \mathrm{C}$ is $0.4 \%$ of the $\mathrm{M}_{\mathrm{w}}$. Here, we accept their estimate as the expanded uncertainty. This leads to an expanded uncertainty of $\mathrm{M}_{\mathrm{w}}$ for this polymer of $0.4 \times 10^{+3} \mathrm{~g} / \mathrm{mol}$.

\subsubsection{Estimating ratio of Glass Rod Scattering to TCB Scattering at $130^{\circ} \mathrm{C}$}

We have 42 repeat measurements of the ratio of the scattering of the glass rod to the scattering 
from the TCB working standard, described in Section 5.5. We take the uncertainty in the repeatability of this experiment as the overall uncertainty in this measurement. Fourteen measurements of the ratio of the glass rod scattering to that of TCB, the working standard, were made for each of three different scattering cells containing TCB. The relative standard deviation of the mean is $0.2 \%$. We take 2 times this uncertainty as the expanded uncertainty from the ratio of the benzene scattering to the glass rod scattering. This yields $0.4 \%$ as the relative expanded uncertainty, or $0.4 \times 10^{+3} \mathrm{~g} / \mathrm{mol}$.

\subsubsection{Uncertainties in the Polarization of Light}

There are two uncertainties associated with the laser light. First, the "vertically polarized" laser beam actually contains "horizontally polarized" components for two reasons: the polarizer inside the laser head lets through a small fraction $\varepsilon$ of the "wrong" polarization and the principal axis of polarization of the light from the laser may not be exactly perpendicular to the optic plane defined by the incident and scattered beams. Both uncertainties will cause light, assumed to be vertically polarized, to contain a small admixture of horizontally polarized light. The effect upon scattering signals from SRM 2886 will be slight, but the effect upon the benzene calibration signals is to change the effective Rayleigh ratio that should have been used toward the $\mathrm{R}_{\mathrm{H}, \mathrm{V}+\mathrm{H}}$ value. The resulting uncertainty in $M_{w}$ is $\varepsilon /(1-\varepsilon)$ for the first effect and $\tan ^{2} \alpha$, where $\alpha$ is the angular missetting, for the second. We take $\varepsilon=1 / 500$ and $\alpha=5^{\circ}$. Then the relative expanded uncertainty from $\varepsilon$ is less than $0.2 \%$ with at least a $95 \%$ level of confidence considering the liberal boundaries assigned to the constituent uncertainties. The uncertainty from $\alpha$ is less than $0.8 \%$ with at least a $95 \%$ level of confidence considering the liberal boundaries assigned to the constituent uncertainties. Following NIST guidelines we take the root-sum-of-squares from these contributions to yield the standard uncertainty of $0.85 \%$ and the relative expanded uncertainty from this contribution of $1.7 \%$, or $1.5 \times 10^{+3} \mathrm{~g} / \mathrm{mol}$.

\subsubsection{Ratio of Working Standard Scattering to Sample Scattering}

Since photon-counting techniques were employed, there should be no systematic uncertainties from this source. Random uncertainties are reflected in the overall random uncertainty of the $M_{w}$.

\subsubsection{Solvent Density}

For the density of 1 -chloronaphalene at $130^{\circ} \mathrm{C}$, we used the value $1.098 \mathrm{~g} / \mathrm{mL}$ as given in references [10,24]. Following Han, Wagner and Verdier [27], we estimate that this value has a relative expanded uncertainty of $<0.1 \%$. The resulting relative expanded uncertainty on $\mathrm{M}_{\mathrm{w}}$ is just $0.2 \%$, or $0.2 \times 10^{+3} \mathrm{~g} / \mathrm{mol}$. 


\subsubsection{Solute and Solvent Masses}

For the measurements actually used in the final determination of $\mathrm{M}_{\mathrm{w}}$ for SRM 2886, the concentrations employed were nominal $(0.5$ to 2.0$) \mathrm{g} / \mathrm{L}$. Solvent masses were chosen so that the solute masses were always about $0.05 \mathrm{~g}$. Using the uncertainty limit of $0.05 \mathrm{mg}$ we usually assign to the balance used to weigh the PE samples, we have relative expanded uncertainties of $0.1 \%$ in the solute masses. The balance used for solute measurements was regularly checked with a $50 \mathrm{mg}$ mass standard calibrated by the NIST Mass Division and was found to vary by less than $0.01 \mathrm{mg}$ from the standard. The uncertainty in $\mathrm{M}_{\mathrm{w}}$ is then the relative uncertainty in solute masses, or about $0.1 \%$ with at least a $95 \%$ level of confidence. This $95 \%$ confidence interval estimate provides a relative expanded uncertainty of $0.2 \%$, or $0.2 \times 10^{+3} \mathrm{~g} / \mathrm{mol}$.

Solvent masses of at least $30 \mathrm{~g}$ were used in solution preparation. The solvent balance was checked against a $100 \mathrm{~g}$ mass standard and found to be off by less than $0.01 \mathrm{~g}$. The solvent masses were measured to $0.01 \mathrm{~g}$. Thus, there are negligible uncertainties in solvent masses.

\subsubsection{Reflection Correction}

The refractive index of 1 -chloronaphalene at $130{ }^{\circ} \mathrm{C}$ is given as $n_{D}=1.5772$ by an estimate described in Section 5.3. The refractive index of the sample cell is given by the vendor as $\mathrm{n}_{\mathrm{D}}=$ 1.500. Although the wavelength of the reported refractive index of 1-chloronaphalene and of the cell are different from that used in our experiments, these values should be adequate to estimate what will turn out to be an extremely small uncertainty. Han, Wagner and Verdier [27] assumed that the refractive index difference between the sample cell and 1-chloronaphalene was about 0.1 , an extreme overestimation for our case. With that assumption, they found for a scattering system like ours, a reflection correction of 0.1 yields a reflectance factor $\mathrm{f}=2 \times 10^{-3}$. Comparison calculations of $\mathrm{M}_{\mathrm{w}}$ for SRM 1484 with and without this correction show the resulting relative standard uncertainty to be less than $0.01 \%$. The equivalent calculation for SRM 2886 would yield a standard uncertainty of less than $0.01 \%$. We take the uncertainty in the molecular mass from this contribution to be zero.

\subsubsection{Instrumental Misalignment}

The effects of instrument misalignment are difficult to estimate. For the geometry of the current high temperature light scattering instrument, it is expected that any deviation from constancy of I $\sin (\Theta)$ is indicative of instrument misalignment. We look at this effect in two different ways.

First, I $\sin (\Theta)$ values calculated from solvent scattering indicated alignment problems. Whereas these values divided by the intensity at $90^{\circ}$ should be independent of $\Theta$ they showed a fractional variation of $0.6 \%$ to $1.0 \%$. If we assume that the data scales with this uncertainty, we would estimate a relative expanded uncertainty of $0.6 \%$ to $1.0 \%$ in $\mathrm{M}_{\mathrm{w}}$. 
Second, from our experience with the alignment, we would also estimate the maximum misalignment to be $0.2^{\circ}$. We have examined two sets of data by purposefully recomputing the $M_{w}$ putting in a misalignment of $0.2^{\circ}$. They consistently both show for a systematic angle variation of $+0.2^{\circ}$ the $\mathrm{M}_{\mathrm{w}}$ varies by about a fraction of $1.0 \%$ and for an angle of $-0.2^{\circ}$ the $\mathrm{M}_{\mathrm{w}}$ varies by -1.0 $\%$.

Since both estimates of uncertainty yield a maximum expanded uncertainty of about $1 \%$ from misalignment, we estimate a total relative expanded uncertainty arising from instrument misalignment of $1.0 \%$, or $0.9 \times 10^{+3} \mathrm{~g} / \mathrm{mol}$ for SRM 2886 .

\subsubsection{Anisotropy of Solute}

Following Han, Wagner, and Verdier[27], we find that equations for $\mathrm{M}_{\mathrm{w}}$ and $\mathrm{K}^{\prime}$ in Section 5.8 are derived on the assumption that the light scattering from the polyethylene is not depolarized. When the solute is optically anisotropy, $M_{w}$ should be replaced with $M_{w}(1+\varepsilon)$ where the correction term is given by:

$$
\varepsilon=(1 / 45)\left(1 / \mathrm{M}_{\mathrm{w}}\right)\left(<\gamma^{2}>/ \mathrm{M}_{\mathrm{w}}\right)\left[4 \pi \mathrm{n}_{\mathrm{s}} \mathrm{N}_{\mathrm{a}} /(\mathrm{dn} / \mathrm{dc})^{2}\right.
$$

where $<\gamma^{2}>$ is given approximately by $267 \times 10^{-50} \mathrm{~cm}^{6}$ per $\mathrm{CH}_{2}$ group [30, 31]. Thus $<\gamma^{2}>/ \mathrm{M}$ is $1.91 \times 10^{-49} \mathrm{~mL}^{2} / \mathrm{g}$. We estimate $\varepsilon$ for SRM 2886 as 0.0003 . We take this to be a relative expanded uncertainly of $0.03 \%$ on $\mathrm{M}_{\mathrm{w}}$. We consider this correction and uncertainty on this measurement negligible.

\subsubsection{Cutoff of Virial Expansion for SRM 2886}

We refitted the data on all 6 sample sets with and without including a third virial term. As a result we found a change in the $\mathrm{M}_{\mathrm{w}}$ using a fit including only the second virial coefficient and that with a third virial of $+1.1 \%, 1.0 \%, 0 \%, 1.3 \% 0 \%$, and $-1.5 \%$. We take the largest relative expanded uncertainty in the $\mathrm{M}_{\mathrm{w}}$ arising from the cutoff of the virial expansion to be less than $2 \%$ and take that to be the expanded uncertainty, $1.7 \times 10^{+3} \mathrm{~g} / \mathrm{mol}$.

\subsubsection{Scattering Changing during the Measurement: Degradation and other Sources}

By their nature light scattering experiments are of short duration. A number of solutions can be prepared and examined by light scattering in a single day. To avoid instability problems solutions used in the certification of $\mathrm{M}_{\mathrm{w}}$ were prepared and measured on the same day. To test stability we conducted a second set of measurements on the same solutions a few days later. Of the two runs of SRM 2886 where stability was investigated, $M_{w}$ was seen to increase by $2.2 \%$, or $1.9 \times 10^{+3}$ $\mathrm{g} / \mathrm{mol}$, and $4.4 \%$, or $3.8 \times 10^{+3} \mathrm{~g} / \mathrm{mol}$, when the solutions were stored at $130^{\circ} \mathrm{C}$ as long as $2 \mathrm{~d}$ after preparation. Studies of time effects on another polyethylene fraction being certified, SRM 2887, 
revealed both increases and decreases in the measured molecular mass as a function of time. We estimate that the light scattering data used in certification of SRM 2886 were acquired within $12 \mathrm{~h}$ after the solutions were first heated. We take the contribution to the uncertainty due to changes during the first $12 \mathrm{~h}$ of heating to be at most $2 \%$, or $1.7 \times 10^{+3} \mathrm{~g} / \mathrm{mol}$. We take this to be our expanded uncertainty from this part of the measurement.

\subsubsection{Summary}

The combined expanded uncertainties, $\mathrm{U}_{c}$, of SRM 2886 are computed as root-sum-of-squares of the component expanded uncertainties, $\mathrm{u}_{i}$, following the formal NIST policy for evaluating and expressing uncertainty in measurements [14]. In Table 3, we find that the combined expanded uncertainty, $U_{c}$, of SRM 2886 is $6.0 \times 10^{+3} \mathrm{~g} / \mathrm{mol}$.

\subsection{Conclusions}

The $\mathrm{M}_{\mathrm{w}}$ of SRM 2886 by light scattering was determined to be $87.0 \times 10^{+3} \mathrm{~g} / \mathrm{mol}$ with a sample standard deviation of $2.2 \times 10^{+3} \mathrm{~g} / \mathrm{mol}$. A combined expanded uncertainty for this light scattering $\mathrm{M}_{\mathrm{w}}$ determination including all type $A$ and type $B$ uncertainties was $6.0 \times 10^{+3} \mathrm{~g} / \mathrm{mol}$. The intrinsic viscosity of SRM 2886 by solution viscosity in 1,2,4-trichlorobenzene was determined to be 157.8 $\mathrm{mL} / \mathrm{g}$ with a sample standard deviation of $1.8 \mathrm{~mL} / \mathrm{g}$. The standard deviation on the mean value was $0.4 \mathrm{~mL} / \mathrm{g}$. A combined expanded uncertainty for this intrinsic viscosity determination including all type $A$ and type $B$ uncertainties was $2.1 \mathrm{~mL} / \mathrm{g}$. The bottle-to-bottle variation of the SRM was checked by size exclusion chromatography and found to be negligible.

\section{Acknowledgements}

The authors would like to thank Charles Han for the use of his high temperature light scattering instrument and his help and discussions concerning this project. Sachin Bhatt assisted with the viscosity measurements. 
Table 1

Contributions to Expanded Uncertainty in Measured Intrinsic Viscosity of SRM 2886

\begin{tabular}{ll}
\hline \multicolumn{1}{c}{ Source of Uncertainty } & Uncertainty $(\mathrm{mL} / \mathbf{g})$ \\
\hline Shear rate dependence & \\
\hline Solvent density, $\rho(0)$ & 0.0 \\
\hline Polymer specific volume, $v_{\text {ave }}$ & 0.4 \\
\hline Buoyancy corrections & 0.04 \\
\hline Solute masses & 0.0 \\
\hline Solvent masses & 0.8 \\
\hline Timer & 0.0 \\
\hline Flow time correction factor & 0.1 \\
\hline Measurement temperature & 0.3 \\
\hline Sample uncertainty in fit of data & 0.5 \\
\hline Combined Expanded Uncertainties & 1.8 \\
\hline
\end{tabular}

Table 2

$M_{w}, A_{2}$ and $R_{g}$ from Light Scattering

\begin{tabular}{llll}
\hline File Name & $\mathbf{M}_{\mathbf{w}}(\mathrm{g} / \mathrm{mol})$ &. $\mathbf{A}_{2}\left(\mathrm{~mol} \mathrm{~mL} / \mathrm{g}^{2}\right)$ & $\mathbf{R}_{\mathrm{g}}(\mathbf{n m})$ \\
\hline & & $\cdot$ & \\
\hline ZA981001 & 87696 & 0.001350 & 18.9 \\
\hline ZA981008 & 84824 & 0.001208 & 18.2 \\
\hline ZA981022 & 83208 & $0: 001276$ & 21.8 \\
\hline ZA981110 & 88550 & $0: 001175$ & 21.8 \\
\hline ZA981203 & 88222 & 0.001274 & 21.2 \\
\hline ZA981216 & 89277 & 0.001185 & 23.1 \\
\hline & & & \\
\hline Average & 86963 & 0.001244 & 20.8 \\
\hline Std deviation & 2394 & $6.8 \mathrm{E}-05$ & 1.8 \\
\hline Uncertainty, mean & 1071 & $3.0 \mathrm{E}-05$ & 0.83 \\
\hline
\end{tabular}


Table 3

Contributions to Combined Expanded Uncertainty

Of the $M_{w}$ of SRM 2886

\begin{tabular}{lc}
\hline \multicolumn{1}{c}{ Source of Uncertainty } & $\begin{array}{c}\text { Contribution } \\
\left(10^{+3} \mathrm{~g} / \mathrm{mol}\right)\end{array}$ \\
\hline Expanded Uncertainty from standard deviation of the mean & 2.2 \\
\hline Solvent index of refraction & 0.1 \\
\hline Calibration of differential refractometer & 1.7 \\
\hline Differential refractive index & 2.5 \\
\hline Wavelength of light & $<0.1$ \\
\hline Rayleigh ratio of scattering standard, benzene & 3.4 \\
\hline Ratio scattering benzene to glass rod at room temperature & 0.6 \\
\hline Temperature dependence glass rod & 0.4 \\
\hline Ratio Scattering glass rod to TCB scattering standard & 0.4 \\
\hline Polarization of light & 1.5 \\
\hline Ratio of standard scattering to sample scattering & $<0.1$ \\
\hline Solvent density & 0.2 \\
\hline Solute and solvent masses & 0.2 \\
\hline Light reflection & 0.0 \\
\hline Instrumental misalignment & 0.9 \\
\hline Anisotropy of polymer in solution & $<0.1$ \\
\hline Truncation of virial expansion & 1.7 \\
\hline Scattering change during the scattering measurement & 1.7 \\
\hline & \\
\hline Combined expanded uncertainty *, $U_{c}$ & 6.0 \\
\hline * by root-sum-of-squares [14] & \\
\hline
\end{tabular}




\section{References}

[1] "Standard Practice for Dilute Solution Viscosity of Polymers" D2857-95, Annual Book of ASTM Standards, Vol 08.02 2000, ASTM, Philadelphia, PA

[2] Peter H. Verdier and Herman L. Wagner, "The Characterization of Linear Polyethylene SRM's 1482, 1483, and 1484. I. Introduction" NBS Special Publication 260-61, P.H. Verdier and H.L. Wagner ed. December 1978 or National Bureau of Standards, Journal of Research, Vol. 83, No. 2, March - April, 1978, pg. 169-171.

[3] M. G. Natrella, "Experimental Statistics", National Bureau of Standards Handbook 91, U.S. Department of Commerce, 1963

[4] Charles M. Guttman and John R. Maurey, "Recertification of Standard Reference Material 1475a, A Linear Polyethylene Resin", NISTIR 5199, 1993

[5] L. Huber, "Application of the Diode-Array Detector in HPLC", Hewlett Packard, France, $08 / 89$, pg. 89-100

[6] Barry J. Bauer, Brian Dickens and William Blair, "Chromatographic Examination of Intaglio Inks, Resins and Varnishes", NISTIR 4949, 1991

[7] Charles M. Guttman, William R. Blair, John R. Maurey, "Recertification of SRM 1482a, a Polyethylene", NISTIR 6054, 1997

[8] "PC-OMNITAB: An Interactive System for Statistical and Numerical Data Analysiș, available from National Technical Information Service, Technology Administration, U.S. Department of Commerce, Springfield, VA 22161

[9] See for example Howard W. Alexander "Elements of Mathematical Statistics", John Wiley \& Sons, 1961, pg. 165-170 or K. A. Brownlee "Statistical Theory and Methodology in Science and Engineering," John Wiley \& Sons, Inc., 1960, pg. 56.

[10] Richard G. Christensen, "The Characterization of Linear Polyethylene SRM 1475 V. Solution Viscosity Measurements" NBS Special Publication 260-42, H.L. Wagner and P.H. Verdier, Editors. September 1972 or National Bureau of Standards, Journal of Research, Vol. 76A, No. 2, March - April 1972, pg. 147-148.

[11] Herman L. Wagner and Peter H. Verdier, "The Characterization of Linear Polyethylene SRM's 1482, 1483, and 1484. IV. Limiting Viscosity Numbers by Capillary Viscometry" NBS Special Publication 260-61, P.H. Verdier and H.L. Wagner ed. December 1978 or National Bureau of Standards, Journal of Research, Vol. 83, No. 2, March - April, 1978, pg. 195-201. 
[12] "Operating Instructions for the Viscosity Measuring System AVS 400", Schott Gerate, Yonkers NY and Hofheim, Germany

[13] See for example F.W. Billmeyer, Jr, "Textbook of Polymer Science, 2nd edition", Wiley Interscience, NY (1971) pg 84.

[14] B. N. Taylor and C. E. Kuyatt, "Guidelines for Evaluating and Expressing the Uncertainty of NIST Measurement Results." NIST Technical Note 1297, January 1993.

[15] A. Kruis, Z. Physik, Chem. B 34, 13-50 (1936).

[16] R. J. Anderson, Appl. Opt. $\underline{8}, 1508-1509$ (1969).

[17] LDC Analytical, "Instruction Manual for KMX-16 Laser Differential Refractometer" Section 5.3, "Calculation of Calibration Constant," Riviera Beach, FL, USA.

[18] H. L.Wagner and C.A.J.Hoeve, J. Poly. Science, Part A-2, 9, 1763-76 (1971). Although this is at a different wavelength we do not expect the overall variation to be wavelength dependent.

[19] J. Horska, J. Stejskal, and P. Kratochvil, "Refractive Increments of Polyolefins", J. Appl. Polym. Sci.,Vol 28, p3873(1983)

[20] J. Horska, J. Stejskal, and P. Kratochvil, "Refractive Increments of Polyolefins", J. Appl. Polym. Sci.,Vol 24, p1845(1979)

[21] J. A. Riddick and W. B. Bunger, "Organic Solvents, Phys. Properties and Methods of Purification," Wiley-Interscience, New York, 1970, Table 58, pg 145 or Table 30, pg 107. Also see B. L. Johnson and J. Smith, "Refractive Indices and Densities of Some Common Polymer Solvents," Ch. 2 in "Light Scattering from Polymer Solutions," Ed M. B. Huglin, Academic Press, London and NY (1972).

[22] "Instruction Manual for Laser Light Scattering Goniometers", Brookhaven Instrument Company, Ronkonkoma, New York, May 1984, catalog number BI-IM version 1.4

[23] G. B. Arrowsmith, G. H. Jeffrey, and A. I. Vogel, J. Chem. Soc., pg 2072 (1965)

[24] H. L. Wagner, "The Characterization of Linear Polyethylene SRM 1475. VI. Differential Refractive Index of Polyethylene Solutions" NBS Special Publication 260-42, H.L. Wagner and P.H. Verdier, Editors. September 1972 or National Bureau of Standards, Journal of Research, Vol. 76A, No. 2, March - April, 1972, pg. 151-155

[25] W. Kaye and J. B. McDaniel, Appl. Opt., 13, 1934-1937 (1974). 
[26] J. Ehl, C. Loucheux, C. Reiss, and H. Benoit, Makromol. Chem., 75, 35 (1964).

[27] Charles C. Han, Herman L. Wagner, and Peter H. Verdier, "The Characterization of Linear Polyethylene SRM's 1482, 1483, and 1484 III Weight-Average Molecular Weights by Light Scattering." NBS Special Publication 260-61, P.H. Verdier and H.L. Wagner ed. December 1978 or National Bureau of Standards, Journal of Research, Vol. 83, No. 2, March - April, 1978, pg. 185-193.

[28] H. Yamakawa, "Modern Theory of Polymer Solutions," Harper \& Row, N.Y., (1971).

[29] Charles M. Guttman, William R. Blair, John R. Maurey, "Recertification of SRM 706a, a Polystyrene", NISTIR 6091, 1998.

[30] "Instruction Manual for Laser Light Scattering Goniometers", Brookhaven Instrument Company, Ronkonkoma, New York, May 1984, catalog number BI-IM version 1.4

[31] H. Utiyama, "Calibration and Correction Factors," Ch. 4 in "Light Scattering from Polymer Solutions," Ed M. B. Huglin. pp 61-88, Academic Press, N.Y., (1972). 


\section{Appendix I}

\section{Purification Procedure for Polyethylene Fractions}

The polyethylene fractions used in preparation of this new Standard Reference Material were purified by recrystallization prior to certification. The recrystallization was conducted in 1,2,4trichlorobenzene, TCB, (Aldrich Chemical Corp) containing about $0.1 \mathrm{~g} / \mathrm{L}$ of antioxidant (Monsanto SANTONOX R).

\section{Recrystallization Apparatus}

The recrystallizations were conducted in a $22 \mathrm{~L}$ reaction flask situated in a well-ventilated hood. The reaction flask was equipped with a stirring apparatus consisting of a Teflon paddle attached to a stainless steel stirring shaft covered by a Teflon sheath. A stirring rate of (20 to30) Hz was found adequate to maintain a thorough mixing of the contents of the flask; higher stirring rates resulted in vortexing and splashing of the contents. The contents of the flask were routinely sparged with dry $\mathrm{N}_{2}$ gas throughout the recrystallization process.

Considering the corrosion potential of the solvent, all internal surfaces of the recrystallization apparatus were either glass or Teflon. A thermometer installed in a glass tube extending down into the solution monitored the temperature of the contents of the flask. The sparging $\mathrm{N}_{2}$ gas was introduced through a stainless steel tube with a Teflon tube sheath, and with a Teflon check valve (Berghof/America) on the end to prevent back flow of the solvent into the tube. $\mathrm{A} \mathrm{N}_{2}$ minimum flow pressure of $3.5 \mathrm{kPa}$ was required to maintain the valve open. The drain valve at the bottom of the reaction flask was connected to the drain tube by an O-ring joint sealed by a Teflon encapsulated silicone rubber O-ring (Sealmor Industries, Factoryville, PA). The drain valve was fabricated from a glass vacuum valve with Teflon O-ring seals.

Hemispherical mantles located at the top and bottom of the flask provided the heat. The top hemispherical mantle had one heating coil identified as the top heater in this description. The bottom hemispherical mantle had two heating coils identified as the bottom heater and mid heater in this description. A single Variac transformer controlled the top and bottom heaters that provided the heat when either constant temperature or very slow cooling was required, or to produce heat rapidly when rapid increase in temperature was required. The mid-heater, energized by a mantle temperature controller (GLAS-COL Mantle Minder II), provided temperature control. The controller responded to the temperature indicated by an iron-constantan thermocouple with its hot junction inserted in the interface between the bottom mantle and the flask at the level of the mid-heater.

\section{Filtration Apparatus}

After the recrystallization process had been completed, purified polyethylene crystals were recovered from the TCB liquor by passing the mixture through the drain valve into a Whatman no. 50 filter cup (Whatman International Ltd., Maidenstone, UK) in a thermostatted Buchner funnel. 
The filter cup was formed by folding pleats into the peripheral margin of a Whatman no. 50 filter paper in such a manner that the pleated periphery of the paper formed a cylindrical wall around the flat bottom center. The resulting cylindrical shaped filter cup fit closely inside the Buchner funnel. The funnel was thermostated by a funnel mantle (GLAS-COL) energized by another temperature controller (GLAS-COL Mantle Minder II). This controller sensed the funnel temperature by an iron-constantan thermocouple with its hot junction inserted in the interface between the funnel and its mantle.

\section{General Recrystallization Procedure}

A few liters TCB were added to the recrystallizing flask and sparging with $\mathrm{N}_{2}$ gas commenced. Sparging with $\mathrm{N}_{2}$ gas was initiated before adding the polymer. A weighed amount of polymer was introduced into the flask through a powder funnel. Additional TCB was added through the long stem powder funnel to achieve the desired solution concentration.

Stirring was initiated and rapid heating was applied to increase the temperature of the TCBpolymer mixture to attain complete dissolution. The mantle temperature controller was preset to control the energy to the mid-heater at the temperature required to dissolve the polyethylene completely. As the contents of the flask approached the solution temperature, the Variac potential to the top and bottom heaters was reduced to approximately ( 15 to 20$) \mathrm{V}$, and the temperature controller was fine adjusted to cycle on and off at the selected temperature.

During dissolution substantial accumulations of polymer, melted but not yet dissolved, adhered to the stirring shaft, thermometer tube, and sparging tube at the top surface of the hot TCB. The solution temperature was maintained until all visible traces of such polymer melt had disappeared, and continued for approximately an additional hour to ensure that the entire polymer had been completely dispersed into solution before initiating rapid cool.

After the polymer had been completely dissolved, rapid cooling was initiated by switching off power to all heaters and opening the top hemispherical mantle to obtain optimal exposure of the top of the flask to the drafts inside the hood. The temperature declined at a rate of approximately $20^{\circ} \mathrm{C} / \mathrm{h}$ during the rapid cooling process. At the end of the rapid cooling process, the top mantle was again positioned about the flask and the temperature was controlled at a level approximately (10 to 20$)^{\circ} \mathrm{C}$ above the recrystallization temperature, for approximately $1 / 2 \mathrm{~h}$ before initiating near equilibrium cooling down to recrystallization. The temperature controls were then reset to initiate pseudo-equilibrium cooling through the recrystallization temperature. The mantle temperature controller was reset to control at a level approximately $10^{\circ} \mathrm{C}$ below the recrystallization temperature. The Variac was reset to provide a constant potential, to the top and bottom heaters, slightly inadequate to maintain the temperature of the solution at the beginning of the near equilibrium cooling process.

Over the course of recrystallizing the polyethylene fractions, the observed cooling rate appeared to be approximately ( 1 to 3$)^{\circ} \mathrm{C} / \mathrm{h}$ at the beginning of the near equilibrium cooling process. The cooling process was left to proceed unattended overnight. The cooling rate would be expected to 
diminish continuously as the solution temperature would approach equilibrium with the constant heat from the top and bottom heaters. Under these conditions, the cooling rate probably diminished to approximately ( 1 to 2$)^{\circ} \mathrm{C} / \mathrm{h}$ at the temperature level where the polymer began to crystallize. After the near equilibrium cooling had been left to proceed overnight, the flask contained an abundance of crystal dispersed in the TCB.

\section{Filtration}

It was advantageous to continue stirring the contents of the flask in order to maintain dispersion of the PE crystals in the TCB phase, while draining the contents of the flask into the filter. Earlier attempts were made to condense the crystals as a slurry before filtration, by discontinuing stirring and allowing the PE crystal to float to the top of the TCB phase. This effort resulted in the drain valve becoming clogged with the PE slurry.

When fractional recrystallization was required to separate a high molecular mass (HWM) PE fraction from its mixture with a low molecular mass (LMW) PE fraction, the filter funnel was thermostatted at a temperature approximately halfway between the recrystallization temperatures of the two fractions.

After all the mobile phase TCB had been drained into the filter, a substantial amount of recrystallized PE remained deposited at the bottom of the flask, and as lumpy aggregates on the stirring shaft, on the thermometer tube, and on the sparging tube. The filtration apparatus was removed and replaced by an extraction beaker. The stirring apparatus was disconnected, and the stirring shaft and paddle were applied as a tool to scrape these recrystallized PE aggregates loose and into the drain valve. Xylene was used at ambient temperature to wash most of the remaining deposits off the inside surfaces of the flask, and down the drain into the extraction beaker.

The recrystallization flask was cleaned by refluxing xylenes at the conclusion of the recrystallization of each $\mathrm{PE}$ fraction. One $\mathrm{L}$ of xylene was added to the flask, and the bottom heater of the flask mantle system was energized with $80 \mathrm{~V}$ from the Variac to reflux the xylene. After refluxing for approximately $1 \mathrm{~h}$, the boiling xylene was drained into the beaker, and the wall of the flask was washed down with fresh xylene. The xylene refluxing wash was repeated two more times. The three xylene washes were collected in separate flasks in early application of this wash procedure. The second xylene wash appeared to contain only a faint trace recrystallized $\mathrm{PE}$, if any, on cooling, and no crystal could be seen in the third wash. Thus, the triple xylene refluxing wash was considered adequate to remove the PE from the recrystallizing flask and drain valve.

\section{Extraction of Residual Solvent}

After the early attempts to extract residual TCB with petroleum ether alone, a procedure was developed to first apply a triple extraction with warm xylenes, followed by triple extraction with petroleum ether before drying in a vacuum oven. Results indicated that this extraction procedure removed the residual TCB content exhaustively. 


\section{Extraction in Xylene}

The polyethylene crystals recovered in the filter cup inescapably contained some residual TCB, and also contained a small amount of low molecular mass PE when the fractional recrystallizations were conducted to recover a high molecular mass PE from its mixture with a minor low molecular mass component. The high molecular mass crystal, recovered by fractional recrystallization of such mixtures, was extracted in warm xylene to remove the residual low molecular mass contaminant as well as the residual TCB content.

The recovered PE fraction was stirred vigorously in a beaker of xylene for at least $1 \mathrm{~h}$, at a temperature approximately $(10 \text { to } 20)^{\circ} \mathrm{C}$ below its recrystallization temperature. When removal of residual low molecular mass PE contaminant from recrystallized high molecular mass PE was also part of the objective, the xylene extraction temperature was also maintained in a range (10 to 20$)^{\circ} \mathrm{C}$ above the recrystallization temperature of the low molecular mass fraction, to insure dissolution of the contaminant. The recrystallization temperatures of both low and high molecular mass components of the starting mix had been determined in an earlier exploratory fractional recrystallization with a sample of such a bimodal starting mixture in TCB.

The warm xylene-crystal mix was poured into a Whatman no. 50 filter cup in the Buchner funnel. The filtrate from the first such xylene extract was discarded without observation. This xylene extraction process was applied at least three times to each crystal preparation.

In the extraction of the PE crystal preparations from fractional recrystallization of mixtures of low and high molecular mass components, the filtrates from the second and third xylene extracts were transferred to separate $2 \mathrm{~L}$ flasks and observed for crystal content after being allowed to cool undisturbed. The very small amount of crystal, which formed in the second filtrate, indicated that almost all the low molecular mass contaminant had already been removed in the first xylene extract. No visually detectable crystal could be found in the filtrate from the last xylene extract after it had been left undisturbed at ambient temperature overnight. This observation was accepted as indication that the contaminant had been removed exhaustively.

\section{Extraction in Petroleum Ether}

The PE crystal preparation, recovered in the filter cup from the final xylene extraction, was then extracted in petroleum ether to remove the residual xylene content and possible trace TCB. The polymer was stirred vigorously for at least $1 \mathrm{~h}$ in a volume of petroleum ether (approx. $1.5 \mathrm{~L}$ to $2 \mathrm{~L}$ ) adequate to maintain fluid mobility of the mixture at ambient temperature. The extract mixture was then poured into a Whatman no. 50 filter cup in the Buchner funnel at ambient temperature. The PE crystals were transferred from the filter back into the extraction beaker, and the petroleum ether extraction repeated. The PE crystal was extracted in three changes of petroleum ether. The petroleum ether extraction was attended by intense electrostatic charging of the polymer. The accumulating electrostatic charge caused imposing problems in transferring the polymer. 


\section{Removal of Residual Liquids by Vacuum Heating}

Although the total extraction process had probably removed the TCB and xylene exhaustively, the polymer may retain residual petroleum ether content. Atmospheric moisture had also been observed to condense on the polymer as it was cooled by evaporation of petroleum ether.

Early experience demonstrated that the PE recovered in the filter cup from the final petroleum ether extraction would become a tough, tightly cohesive spongy material if left undisturbed for several hours. Therefore, the purified PE crystals were finely divided using a spatula immediately following filtration of the final extraction by petroleum ether. The PE was easily mashed with a stainless steel spatula on clean paper trays, however severe charging was encountered if a Teflon surface was part of the mashing process (Teflon spatula or sheet).

The polymer was left on the paper trays covered with clean paper sheets at ambient temperature for a few days to allow the static charge to dissipate before attempting a transfer to containers. After the charge had been given time to dissipate, the polymer was transferred from the paper trays into reweighed ointment jars, attended by moderate charge problems.

The jars were placed in a vacuum oven and loosely covered with disks of filter paper in order to easily vent any vapors, which the polymer might yield in the heated vacuum. The polymer was maintained at $50{ }^{\circ} \mathrm{C}$, and a vacuum pulled through a liquid nitrogen cold trap. The vacuum heating was continued until no more condensate was collected in the cold trap.

\section{Appendix II}

\section{Purification of the Light Scattering Solvent, 1-Chloronapthalene}

The vacuum distillation was conducted with a $1 \mathrm{~m}$ vacuum jacketed column packed with glass helices (Ace Glass G-6720-124). The column was connected to a $5 \mathrm{~L}$ round bottom flask heated by hemispherical mantles. A pump line vacuum controlled with a variable Hg-column manostat evacuated the still. The vacuum line contained a liquid nitrogen cold trap and an Emil Greiner $\mathrm{Hg}$-U-tube vacuum indicator spliced into the vacuum line between the still and the manostat. A Friedrichs condenser was connected to the top of the column to remove the beta-isomer impurity.

The solvent purification began with about ( 3 to 3.5) $\mathrm{L}$ of the starting liquid in the round bottom flask with SiC boiling chips, and the Friedrichs condenser connected to the top of the column. Vacuum was applied with the manostat adjusted to control the residual pressure at about $3.5 \mathrm{kPa}$. The 1-chloronaphthalene was refluxed in the still overnight to allow impurities (2chloronaphthalene) to crystallize out from the hot vapor onto the condenser. The vacuum refluxing was interrupted to remove the separated 2-chloronaphthalene from the Friedrichs condenser. The condenser was disconnected from the column and cleansed free of the crystallized impurity by refluxing hot acetone vapors from a flask below that was heated by a hot air gun. 
Residual acetone vapor was purged from the condenser by a steam of filtered air applied for about $1 \mathrm{~h}$. The cleaned Friedrichs condenser was then reconnected to the column to resume the refluxing process. This entire process was repeated 2 or 3 times, until no trace of crystallized impurity could be seen in the Friedrichs condenser, and then a few times more in order to ensure exhaustive removal of the 2-chloronaphthalene.

In order to remove any possible trace impurity from the column, an acetone flask replaced the chloronaphthalene flask, and acetone refluxed in the column and Friedrichs condenser at ambient pressure overnight. The still was disconnected from the acetone flask, and a stream of filtered air was passed through the still overnight to purge residual acetone vapor.

Once the 2-chloronaphthalene had been exhaustively removed, the refluxing was terminated and the distillation of 1-chloronaphalene begun. The Friedrichs condenser was replaced with a vacuum distilling head, and the column reconnected to the chloronaphthalene flask. With the vacuum pulled down to a residual pressure controlled at about $35 \mathrm{k} \mathrm{Pa}$, the solvent was refluxed overnight to allow the low boiling impurities to concentrate in the headspace at the top. The first (50 to 100 ) $\mathrm{mL}$ of distillate was collected in a small waste flask. The next (1 to 2 ) L purified 1 chloronaphthalene was retained as solvent for polyethylene characterization experiments. 


\title{
Appendix III \\ DRAFT CERTIFICATE
}

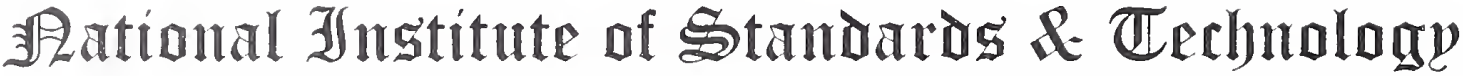

\section{Certificate of Analysis}

\section{Standard Reference Material ${ }^{\circledR} 2886$}

\author{
Polyethylene
}

This Standard Reference Material (SRM) is intended primarily for use in calibration and performance evaluation of instruments used to determine the molar mass ${ }^{a}$ and molar mass distribution by size cxclusion chromatography (SEC). A unit of SRM 2886 consists of approximately $0.3 \mathrm{~g}$ of polyethylene powder.

Tablc 1. Certified Mass-Average Molar Mass and Intrinsic Viscosity

$\begin{array}{ccc}\text { Property } & \text { Certificd Value } & \text { Uncertainty } \\ \text { Mass-Averagc Molar Mass }\left(\mathrm{M}_{w}\right), \mathrm{g} / \mathrm{mol} & 87.0 \times 10^{3} & \pm 6.0 \times 10^{3} \\ \text { Intrinsic Viscosity }[\eta], \mathrm{mL} / \mathrm{g} \text { in } 1,2,4- & 157.8 & \pm 2.1\end{array}$
trichlorbcnzenc at $130^{\circ} \mathrm{C}$

${ }^{a}$ Expresscd as molar mass, previously expressed as molecular weight [1].

Certified Values and Uncertainties: The ccrtified value for $\mathrm{M}_{\mathrm{w}}$ was mcasured on SRM 2886 using static light scattering with 1-chloronaphthalene as solvent at $130^{\circ} \mathrm{C}$ [3]. The certified value for intrinsic viscosity was determined in $1,2,4-$ trichlorobenzene $(\mathrm{TCB})$ at $130^{\circ} \mathrm{C}$.

The certified measurement uncertainty is cxpressed as a combined expanded uncertainty with a coverage factor $\mathrm{k}=2$, calculated in accordance with NIST procedure [2]. Type A and Type B contributions to the expanded uncertainty of the measured mass-averagc molar mass include the unccrtainties in Raylcigh ratio of the scattering standard, optical alignment, and calibration of the differential refractometer.

Expiration of Certification: The certification of SRM 2886 is valid until 01 January 2008, within the measurement uncertaintics specified, provided that the SRM is handled in accordance with the storage instructions given in this certificate. This certification is nullified if the SRM is modificd or contaminated.

Maintenance of SRM Certification: NIST will monitor this SRM over the pcriod of its ccrtification. If substantive technical changes occur that affect the certification before expiration of this certificate, NIST will notify the purchaser. Return of the attached registration card will facilitate notification.

The technical coordination leading to certification of this SRM was provided by B.M. Fanconi of the NIST Polymers 
Division. The technical measurement and data interpretation were provided by C.M. Guttman, W.R. Blair, and J.R. Maurey of the NIST Polymers Division.

The support aspects involved in the preparation, certification, and issuance of this SRM were coordinated through the NIST Standard Reference Materials Program by J.W.L. Thomas.

Eric J. Amis, Chief Polymers Division

Gaithersburg, MD 20899

Certificate Issue Date: 9 February 2001

Nancy M. Trahey, Chief Standard Reference Materials Program

Storage: The SRM should be stored in the original bottle with the lid tightly closed under normal laboratory conditions.

Homogeneity and Characterization: The homogeneity of SRM 2886 was tested by SEC analysis of solutions in TCB at $130^{\circ} \mathrm{C}$. The characterization of this polymer is described in Reference 3. SRM 2886 is a cleaning up, blending, and rebottling of the fractionation of SRM 1475. It was produced in the same fractionation as SRM 1482, SRM 1483 and SRM 1484 [4].

\section{REFERENCES}

[1] Taylor, B.N., "Guide for the Use of the International System of Units (SI)," NIST Special Publication 81 1, 1995 Ed., (April 1995).

[2] Guide to the Expression of Uncertainty in Measurement, ISBN 92-67-10188-9, $1^{\text {st }}$ Ed. ISO, Geneva, Switzerland, (1993): see also Taylor, B.N., and Kuyatt, C.E., "Guidelines for Evaluating and Expressing the Uncertainty of NIST Measurement Results," NIST Technical Note 1297, U.S. Government Printing Office. Washington D.C., (1994).

[3] Guttman, C.M., Maurey, J.R. , and Blair, W.R., "Certification of the Relative Molecular Mass and the Intrinsic Viscosity of SRM 2886, a Polyethylenc of Narrow Molecular Mass Distribution," NISTIR 6487, 2001.

[4] Peter H. Verdier and Herman L. Wagner, "The Characterization of Linear Polyethylene SRM's 1482, 1483, and 1484. I. Introduction" NBS Special Publication 260-61, P.H. Verdier and H.L. Wagner ed. December 1978 or National Bureau of Standards, Journal of Research, Vol. 83, No. 2, March - April, 1978, pg. 169-171. 

